(2) Open Access Full Text Article

REVIEW

\title{
Neuropathic cancer pain:What we are dealing with? How to manage it?
}

This article was published in the following Dove Press journal:

OncoTargets and Therapy

17 April 2014

Number of times this article has been viewed

\author{
Ece Esin \\ Suayib Yalcin \\ Medical Oncology Department, \\ Hacettepe University Cancer \\ Institute, Ankara, Turkey
}

Correspondence: Suayib Yalcin Medical Oncology Department, Hacettepe University Cancer Institute, Sihhiye, Ankara 06I00, Turkey

Tel +90 3123052929

Fax +90 312305 2935

Email suayibyalcin@gmail.com
Abstract: Cancer pain is a serious health problem, and imposes a great burden on the lives of patients and their families. Pain can be associated with delay in treatment, denial of treatment, or failure of treatment. If the pain is not treated properly it may impair the quality of life. Neuropathic cancer pain (NCP) is one of the most complex phenomena among cancer pain syndromes. NCP may result from direct damage to nerves due to acute diagnostic/therapeutic interventions. Chronic NCP is the result of treatment complications or malignancy itself. Although the reason for pain is different in NCP and noncancer neuropathic pain, the pathophysiologic mechanisms are similar. Data regarding neuropathic pain are primarily obtained from neuropathic pain studies. Evidence pertaining to NCP is limited. NCP due to chemotherapeutic toxicity is a major problem for physicians. In the past two decades, there have been efforts to standardize NCP treatment in order to provide better medical service. Opioids are the mainstay of cancer pain treatment; however, a new group of therapeutics called coanalgesic drugs has been introduced to pain treatment. These coanalgesics include gabapentinoids (gabapentin, pregabalin), antidepressants (tricyclic antidepressants, duloxetine, and venlafaxine), corticosteroids, bisphosphonates, $\mathrm{N}$-methyl-D-aspartate antagonists, and cannabinoids. Pain can be encountered throughout every step of cancer treatment, and thus all practicing oncologists must be capable of assessing pain, know the possible underlying pathophysiology, and manage it appropriately. The purpose of this review is to discuss neuropathic pain and NCP in detail, the relevance of this topic, clinical features, possible pathology, and treatments of NCP.

Keywords: neuropathy, cancer pain, coanalgesics

\section{Introduction}

Cancer pain is a serious health problem, and imposes a great burden on the lives of patients and their families. Pain can be encountered in every stage of cancer until the end of life, and may interfere with the patient's treatment process, lead to treatment refusal, and substantially impair quality of life. Today, although many treatment options for cancer are available, there is still no cure for some malignancies; therefore, a peaceful end of life is a privilege. All practicing oncologists must be capable of assessing pain, know the possible underlying pathophysiology, and manage it appropriately.

\section{Methodology}

A literature search was conducted on November 3, 2013 on the PubMed and Cochrane databases using the following keywords: neuropathy, pain, cancer, neuropathic pain (NP), cancer pain, oncology, chemotherapy, pharmacology, non-pharmacologic treatment, genetic mechanisms, resistance, opioid, coanalgesic. Articles reporting data for 
cancer and noncancer patients and neuropathy and NP were chosen to be eligible for our review. Abstracts of the articles were reviewed independently by the two authors (EE and SY). The original articles and reviews for which we could obtain full texts were chosen. All of the references cited were agreed upon by the two authors.

\section{Pain-related definitions}

The International Association for the Study of Pain (IASP) defines NP as an unpleasant, multidimensional, sensory, and emotional experience associated with actual or potential tissue damage or described in relation to such damage. ${ }^{1,2}$ Pain can be described in two major categories: adaptive pain and maladaptive pain. Adaptive pain is a protective mechanism that provides survival benefit or contributes to the healing process. In contrast, maladaptive or chronic pain is a disorder that represents pathology of neural structures. Chronic pain has been defined as a pain that lasts beyond the duration of insult to the body or beyond the duration of the healing process. ${ }^{1,3,4}$ Pain can be categorized as two main types: nociceptive pain, which is developed by a noxious stimulus to a tissue (somatic nociceptive pain) or to a visceral organ (visceral nociceptive pain), and NP, which arises from abnormal neural function as a result of direct damage or indirect insult to a neural tissue involved in pain processing. Pain can be also be described according to the response given to underlying altered sensation. This terminology is summarized in Table 1.

Neuropathy is the result of pathological change or functional disturbance in nerves. If only one nerve is affected, it is called mononeuropathy. When only a few nerves are affected, this is described as mononeuropathy multiplex; if nerves are affected diffusely and bilaterally, than it is called polyneuropathy. 1,5 Although the IASP first published its pain terminology in 1979, neuropathy was included in this list only after 1994., ${ }^{1,6}$

The original definition of NP involves both lesion and dysfunction. In a broader sense, this could easily define the neuropathy, but the term "dysfunction" created some arguments in the literature in 2002 and 2004. The definition was narrowed by the IASP so that neuropathy consists of a lesion either in the peripheral nervous system (PNS) or the central

Table I Terms used for classification of pain-related symptoms

\begin{tabular}{ll}
\hline Hyperalgesia & Attenuated pain response to a painful stimulus \\
Hypoalgesia & Diminished response to a painful stimulus \\
Allodynia & $\begin{array}{l}\text { Pain that is associated with an unpainful stimulus } \\
\text { (light touch, mild temperature) }\end{array}$ \\
Dysesthesia & $\begin{array}{l}\text { An abnormal sensation that is developed by a } \\
\text { normal stimulus }\end{array}$ \\
\hline
\end{tabular}

nervous system (CNS) or both. As the nature of this type of pain is studied further, the excitability and plasticity of the nervous system become increasingly important, so treatment approaches have focused on pathophysiology rather than etiology. The Neurology and Pain Community introduced a new definition in 2008 in order to clarify the issue, which defines neuropathy as a pain arising as a consequence of either a lesion or disease affecting the somatosensory system. ${ }^{7}$ This definition is good in terms of classification of neurological diseases, but NP is a condition that involves multiple specialties.

Generally speaking, NP can be subdivided into three categories: sympathetically mediated pain, peripheral NP pain, and central pain. Sympathetically mediated pain arises in a PNS tissue, but is associated with autonomic changes (formerly known as reflex sympathetic dystrophy). Peripheral NP occurs due to damage to PNS components without the involvement of the autonomic system. Central pain stems from abnormal CNS activity. ${ }^{8}$

The current National Comprehensive Cancer Network (NCCN) Clinical Practice Guidelines for Adult Cancer Pain (version 1.2013) follows the IASP definition, but also broadens and specifies the assessment of cancer patients, since this category may include more pathophysiologic pathways than others. The NCCN guidelines describe a detailed assessment regarding to both etiology and pathophysiology, as well as specific cancer-related syndromes. ${ }^{9}$ These guidelines are also important in that they draw attention to NP as a medical emergency.

Still, there is no consensus on the definition and assessment strategies of NP. Future studies are thus needed to find a better definition to standardize language in the literature.

\section{Etiopathogenesis of neuropathic pain}

Over the past decade, the pathophysiologies of neuropathic syndromes and NP have been the subject of extensive preclinical and clinical research. ${ }^{10,11}$ Neuropathy syndromes are disorders of the CNS or PNS, whether or not they are associated with a demonstrable lesion. NP is a part of these syndromes. The etiologic condition can be a primary lesion of a nerve or it can indirectly involve the function or conduction pathway of that nerve. Sometimes, the first etiology disappears with time, but pain continues. The most commonly considered theory is that pain is potentially a learned condition. Today, this notion is widely accepted, although it was originally introduced in an evolutionary way. ${ }^{12}$ Peripheral and central mechanisms can play role in NP. Under normal conditions, unmyelinated $\mathrm{C}$ fibers and thinly myelinated $\mathrm{A} \delta$ fibers are responsible for 
the transmission of painful stimuli. They are responsive to high thresholds, but in neuropathic conditions their physiology changes. Spontaneous activity is evident in injured-area neurons. In animal models, ectopic neuronal activation related to malfunctioning sodium or possibly potassium channels in peripheral nerves and dorsal root ganglia have been reported. ${ }^{13-15}$ Peripheral lesions can induce central changes at spinal cord levels or higher in the CNS. ${ }^{10}$ Every step from signal transduction from primary painful stimulus and peripheral nerve plasticity to microglial activation, central stimulus organization, and central neural plasticity can be involved in pathophysiology. ${ }^{11,16,17}$ Central neuronal plasticity and hyperexcitability are probably sensitive to intracellular protein-concentration changes. These changes can be induced by activation of $N$-methyl-D-aspartate (NMDA) receptors by excitatory neurotransmitters. Because of the multiplicity of mechanisms, each of the painful symptoms may correspond to distinct mechanisms, and thus respond to specific treatments. NP syndromes are not typically isolated; most of the time, they are accompanied by nociceptive pain, such as visceral pain, ischemia-induced pain, and inflammatory pain. Conditions associated with NP are summarized in Table 2.

\section{Cancer pain syndromes and neuropathic cancer pain: causes and forms}

Pain can be the presenting symptom of cancer in an otherwise healthy patient or emerge as disease progresses. It may

Table 2 Etiopathogenic disorders associated with neuropathic pain syndromes*

\begin{tabular}{|c|c|}
\hline Toxicity & $\begin{array}{l}\text { Chemotherapy, radiotherapy, arsenic/lead } \\
\text { exposure, statin and isoniazid usage }\end{array}$ \\
\hline Trauma & $\begin{array}{l}\text { Phantom limb pain, postmastectomy pain, } \\
\text { postthoracotomy pain, or any pain in major surgical } \\
\text { regions }\end{array}$ \\
\hline Compression & $\begin{array}{l}\text { Nerve-entrapment syndromes like carpel tunnel } \\
\text { syndrome, direct tumor compression, especially in } \\
\text { tumor metastasis }\end{array}$ \\
\hline Ischemia & $\begin{array}{l}\text { Pain in diabetic food ulcers, vasculitis-associated } \\
\text { neuropathy, Buerger's disease }\end{array}$ \\
\hline Infection & $\begin{array}{l}\text { Postherpetic neuralgia, human immunodeficiency } \\
\text { virus-associated neuropathy, herpes zoster- } \\
\text { associated leprosy }\end{array}$ \\
\hline Congenital diseases & Storage diseases, Fabry's disease, amyloidosis \\
\hline $\begin{array}{l}\text { Autoimmune } \\
\text { disorders }\end{array}$ & $\begin{array}{l}\text { Chronic inflammatory demyelinating } \\
\text { polyneuropathy, multifocal motor neuropathy, } \\
\text { vasculitic neuropathy, and paraneoplastic syndromes } \\
\text { like Eaton-Lambert syndrome, multiple sclerosis }\end{array}$ \\
\hline Metabolic disorders & $\begin{array}{l}\text { Diabetic neuropathy, uremic neuropathy, alcohol } \\
\text { toxicity, beriberi }\end{array}$ \\
\hline
\end{tabular}

Note: *Some of these mechanisms usually coexist in neuropathic pain syndromes. also develop as a treatment complication. It is estimated that $50 \%-90 \%$ of cancer patients encounter pain in their lifetime. ${ }^{18,19}$ In a recent study from Europe, 670 of 1,051 patients were recorded as having pain. ${ }^{20}$ Pain in cancer patients can result from the tumor itself invading or destroying bodily structures, from side effects of treatment modalities, and from comorbid diseases.

Cancer pain syndromes can be either acute or chronic. Acute pain is most frequently associated with diagnostic or therapeutic interventions related to cancer. Diagnostic approaches directly harm tissues, especially nerves, resulting in pain. Chemotherapy/radiotherapy induces acute pain at the beginning of treatment or as a side effect (Table 3).

Chronic pain in cancer can be directly tumor-related or due to treatment strategies. ${ }^{21}$ Chronic cancer pain syndromes are summarized in Table 4 . In the acute setting, cancer pain is troublesome but easier to handle. Pain becomes more disturbing and disappointing for patients and physicians as time passes. Whether cancer pain is either acute or chronic, it must be identified, assessed, and treated dynamically.

Bennett et al estimated that $18.7 \%-21.4 \%$ of cancer patients have neuropathic cancer pain (NCP). According to

Table 3 Acute cancer pain syndromes

Pain related to diagnostic approaches

- Biopsy (bx)-associated pain like bone marrow bx, transrectal prostate bx, or puncture-associated like lumbar puncture or arterial blood gas sampling, etc

- Paracentesis-associated pleurodesis; nephrostomy, biliary stent implantation, etc

- Pathologic fractures due to bony metastasis

- Intestinal/biliary/ureteric obstruction and/or perforation; visceral organ perforation like gastric or colonic tumor

Pain related to treatment (chemotherapy)

- Pain due to oral mucositis

- Acute polyneuropathy

- All-trans retinoic acid-induced bone pain

- Intrathecal chemotherapy induced headache (cerebrospinal fluid leakage or chemical meningitis)

- Fluoropyrimidine-induced angina

- Vasospasm (oxaliplatin)

- Steroid-induced perineal burning

- Painful hand-foot syndrome

- Locoregional chemotherapy pain

- Bone pain due to colony-stimulating factors

- Immunotherapy-associated myalgias (interferon)

- Analgesia-associated opioid-hyperalgesia syndrome or injection-side pain

Pain related to treatment (radiotherapy)

- Mucositis

- Early brachial plexopathy

- Radiation enteritis

- Acute myelopathy 


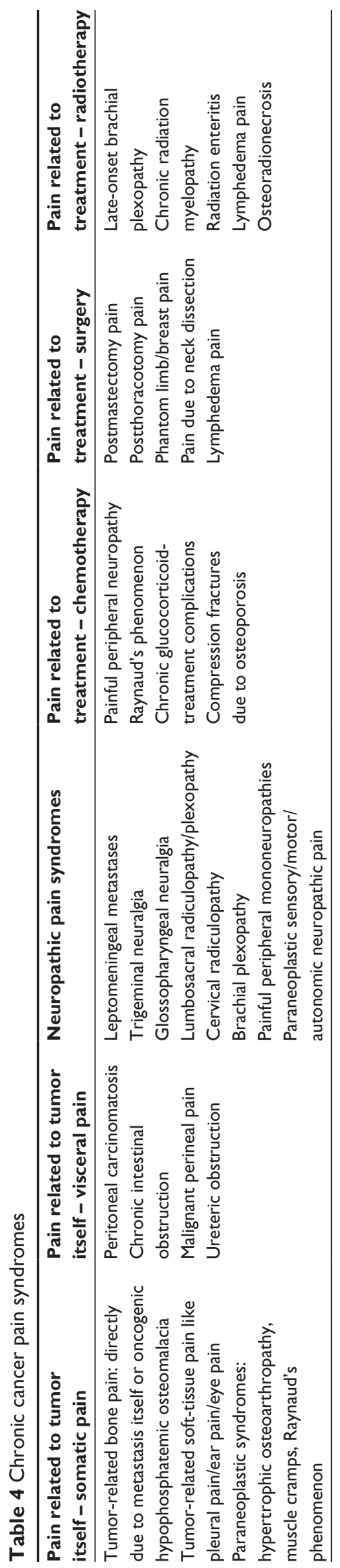

their systematic review, the prevalence of pain syndromes associated with NCP is $19 \%-39.1 \%{ }^{22}$ Recognition of NCP is especially important, since different treatment strategies may be required to successfully overcome it.

NCP is characterized by patients as a spontaneous burning-like sensation and/or intermittent sharp, stabbing-like pain mostly felt at night. Also, patients report burning-like pain sensations in a stocking-and-glove pattern. NCP can be seen in conjunction with motor deficits, deep sensory loss, loss of proprioception and also with dysmotility of enteric organs, bladder dysfunction, pupillomotor abnormalities and orthostatic hypotension. ${ }^{23}$ These additional symptoms worsen the quality of life more, since daily life requirements like dressing and combing hair are affected in addition to functionality. The relationship between the etiology and type/pattern/symptomatology of pain is complex and not well understood. NCP is a multistep process, which explains the presence of diverse clinical presentations. This is why combination-treatment options are necessary for effective pain relief. Besides cancer-related pathologies, disorders like diabetes that already exist can lead to NP or worsen the situation. Psychological conditions, mood disorders, and personality type may influence pain perception and intensity. ${ }^{24-26}$

NCP arises from physical or chemical damage to peripheral or central neurons or in the neural conduction system. Direct nerve damage by tumor pressure, invasion of nerve structure and resulting entrapment, hypoxia, or chemical changes in the tumor microenvironment like inflammatory signaling, proinflammatory cytokine production, and release of tumor algogens can result in NCP. There is a growing body of information on the subject of inflammation in relation to cancer. Inflammatory cells and cytokines are accused of having a role in the development of cancer complications, in addition to carcinogenesis, tumor progression, and metastasis. The neuropathic process and NCP is the intersection of complications of cancer and inflammation. Macrophages and microglia were investigated in the plasticity of visceral neural plexuses, dorsal root ganglion, spinal cord, and CNS broadly. ${ }^{16,17,27,28}$ Mast cells were found to be increased in pancreatic cancer with NP. ${ }^{29}$ Autonomic and enteric neuropathies (eg, in gastric paresis or NCP in pancreatic cancer) have an association with inflammatory signals and neuritis. ${ }^{30}$ Neural plasticity could have a role in the CNS and PNS, and may interact with other carcinogenetic mechanisms. ${ }^{30,31}$ These changes are more unique to NCP than noncancer NP. ${ }^{5,25,32}$ Bone metastasis is an important part of NCP. Bone is a prevalent metastasis site, and related pain 
mechanisms are diverse. NCP related to bone metastasis is time- and energy-consuming for patients and physicians. The afferent sensory fibers of bone, periosteum, osteoclasts, and bone-remodeling balance are important in the development of NCP. Metastatic cancer cells can invade the sensory fibers and initiate pain. Increased osteoclastic activity diminishes bone strength, and thus pathological microfractures can happen, resulting in pain. Mechanical distortion and pressure to the periosteum is the third factor that leads to pain. ${ }^{33-35}$

NCP can be broadly categorized as peripheral (tumor infiltration/pressure, pain due to treatment complication) or central (spinal cord or CNS involvement or treatmentcomplication pain). NCP can also be divided into subgroups, such as pain directly related to tumor involvement, pain associated with chemotherapy, neuropathic syndromes associated with paraneoplastic syndromes, and pain associated with radiotherapy or surgery related NCP. Surgery results in physical damage to afferent neurons, and may cause phantom pain. Radiotherapy creates a hypoxic environment, and hypoxic nerves are more vulnerable. In the long term, chronic hypoxia leads to fibrosis in perineural tissues and causes late onset NP and NCP even in cancer-free survivors. ${ }^{25,36}$

Paraneoplastic neuropathies can be encountered during various malignancies, such as small-cell lung cancer, thymoma, and hematological malignancies, ie, lymphomas. Although the classical feature of paraneoplastic neuropathy is a subacute sensory neuropathy, it can present as sensorimotor neuropathy, brachial plexopathy, vasculitic neuropathies, and autonomic neuropathies also. ${ }^{37}$ These paraneoplastic neuropathies may be related to onconeural antibodies, a term used to describe the antibody secreted from neoplasm or its metastasis that reacts to normal nervous tissue components. Voltage-gated potassium and calcium channels and the collapsin response-mediator protein 5 can be potential targets, and anti-Hu antibodies are responsible most of the time. However, most of the time, none of the known antibodies can be identified. The diversity of symptoms of paraneoplastic neuropathy ranges from paresthesias, pain, and muscle weakness to limbic encephalitis, dysautonomic motility problems (gastric or enteric pseudo-obstruction), and orthostatic hypotension..$^{23,38}$ These paraneoplastic neuropathies may be associated with pain. Paraneoplastic neuropathies can be confused with other types of malignancy-associated NP syndromes and complicate the treatment process. These definitions make NCP easier to understand and recognize in the clinical setting, but generally they do not differ in relation to treatment. Common NCP syndromes are summarized in Table 5.
Table 5 Common neuropathic syndromes associated with cancer

Chemotherapy-induced neuropathy

Tumor invasion: leptomeningeal metastases

Neuralgias: trigeminal neuralgia or postherpetic neuropathy

Glossopharyngeal neuralgia

Radiculopathies and plexopathies: lumbosacral radiculopathy/plexopathy

Cervical radiculopathy/plexopathy

Brachial plexopathy

Painful peripheral mononeuropathies

Paraneoplastic sensory neuropathies

Horner's syndrome

Enteric neuropathies

Eaton-Lambert myasthenic syndrome

Postsurgery neuropathies

Postradiotherapy neuropathies

Paraneoplastic motor neuropathy

Paraneoplastic visceral neuropathy

Pain associated with infectious neuropathies is a main concern during cancer treatment. Infectious neuropathies are a group of disorders mainly encountered with leprosy, hepatitis $\mathrm{C}$ virus, and human immunodeficiency virus (HIV) infections, Lyme disease, and varicella zoster virus (VZV) infections.

VZV reactivation is the most common infectious disease associated with increased risk of neuropathy. It poses a $10 \%-20 \%$ lifetime risk of ganglioneuritis in the general population. ${ }^{39} \mathrm{VZV}$ is a neurotropic virus of the human $\alpha$-herpes virus family. It can cause chickenpox as a primary disease, and can stay latent in neurons of autonomic ganglia, dorsal root ganglia, and ganglia of cranial nerves. Also, the inactivated viruses in VZV vaccine can become dormant. The latent viruses become important as cellular immunity decreases naturally (ie, the aging process) or as a complication of treatment (ie, cancer patients). Reactivation of viruses results in the development of a maculopapular pruritic rush and dermatomal distributed pain.

VZV infection may be followed by multiple neurological complications (encephalitis, meningitis, vasculitis, motor radiculopathies, necrotizing ocular disease, and most commonly postherpetic neuralgia [PHN]). ${ }^{40-42} \mathrm{PHN}$ is an NP syndrome that is persistent after 30-90 days of the healing of a zoster-infection rash. The replication process of viruses destroys the neurons in ganglia and causes the pain syndrome in diverse clinical presentations from allodynia to dysestesia. ${ }^{42}$ PHN risk can be estimated from the intensity of pain in the acute zoster-infection period. However, antiviral therapy to slow down the pathophysiologic mechanism of ganglia injury has not yet been proven. ${ }^{41,43}$ The latent zoster infection and the PHN associated with VZV pose a great burden, especially in immunocompromised patients (hematological malignancies, solid-tumor patients treated with chemotherapy, solid-organ 
transplant patients, and HIV patients), who have higher reactivation rates. ${ }^{39,40,43-46}$

The VZV-reactivation rate is as high as $50 \%$ in hematopoietic stem cell transplant patients without a prophylactic regimen, ${ }^{44}$ and is also higher in patients treated with purine analogs and novel agents like proteasome inhibitors or alemtuzumab. ${ }^{44} \mathrm{PHN}$ can be treated with tricyclic antidepressants (TCAs), gabapentin, pregabalin, long-acting opioids, or tramadol; moderate evidence supports the use of capsaicin cream or a lidocaine patch as a second-line agent. The details of treatment options will be discussed later.

Among all mechanisms, it is estimated that a greater proportion of NCP will be caused by cancer chemotherapy. ${ }^{8,22}$ In a recent European survey, the proportion of chemotherapyinduced NP (CINP) pain among other NCP types was $32.6 \%{ }^{47}$ There are several reports showing that $\mathrm{CP}$ and NCP were diagnosed and treated inefficiently. ${ }^{20,22,48}$ Special attention should be given to common mechanisms of NCP in order to understand better and treat accordingly.

\section{Chemotherapy-induced neuropathy}

The development of more sophisticated chemotherapeutics and optimal-use older drugs enables cancer patients to have excellent outcomes, with more cure potential, and a longer survival chance even if no cure is possible. On the other hand, this improvement may result in serious acute or chronic side effects for "survivors". Neuropathy is one of those side effects that is encountered frequently. The vague symptomatology, indeterminate terminology to define it, and lack of really adjustable and applicable diagnostic criteria lead to underreported NCP by patients and physicians. ${ }^{49,50}$ Still, CINP is the main syndrome among the NCP types. ${ }^{20}$ Chemotherapy-induced neuropathy and CINP depend on the agent used, duration and dosage of treatment and also coexisting other neuropathic disorders. ${ }^{51}$ Although the risk of NP complication is specific to the drug itself, the clinical symptoms and signs of neuropathy and NP are very similar between drugs. Sometimes, the effects are seen as acute or subacute onset, but insidious development is more frequent. The main chemotherapeutic drugs responsible for NCP and CINP are shown in Table 6. ${ }^{25,36,52,53}$

Cisplatin is a mainstay of many chemotherapy regimens for diverse cancer types, such as lymphoid malignancies, lung cancer, and genitourinary cancer. When utilized, the rate of curing testicular cancer rapidly increased. However, neuropathy is the dose-limiting adverse effect of treatment in some of these patients. Cisplatin causes axonal neuropathy, which mostly affects large sensory fibers. Although the pri-
Table 6 Common chemotherapeutic agents involved in neuropathy process

\begin{tabular}{|c|c|c|}
\hline Drug & Type & Onset, duration, recovery \\
\hline Cisplatin & Chronic & I-6 months for onset \\
\hline Carboplatin & Chronic & $\begin{array}{l}\text { Years for recovery (more } \\
\text { than } 80 \% \text { ) }\end{array}$ \\
\hline Oxaliplatin & $\begin{array}{l}\text { Acute or chronic } \\
\text { Cold-induced }\end{array}$ & $\begin{array}{l}\text { Acute: even during infusion } \\
\text { Chronic: same as cisplatin } \\
\text { Years for recovery (more } \\
\text { than } 80 \% \text { ) }\end{array}$ \\
\hline Taxanes & $\begin{array}{l}\text { Chronic, rarely acute } \\
\text { More with dose-dense } \\
\text { taxane treatment }\end{array}$ & $\begin{array}{l}\text { Onset within weeks } \\
19 \% \text { complete recovery } \\
25 \% \text { no recovery } \\
\text { Paclitaxel-associated acute } \\
\text { pain syndrome lasts } 4-5 \text { days }\end{array}$ \\
\hline Vincristine & Subacute & Onset usually after 3 months \\
\hline Vinblastine & Subacute & $\begin{array}{l}\text { Recovery after } 3 \text { months of } \\
\text { drug cessation }\end{array}$ \\
\hline Bortezomib & $\begin{array}{l}\text { Onset any time, mainly } \\
\text { subacute or chronic }\end{array}$ & $\begin{array}{l}\text { Dose reduction is } \\
\text { recommended }\end{array}$ \\
\hline Thalidomide & Dose-dependent & $\begin{array}{l}\text { Recovery at } 2 \text { years or no } \\
\text { recovery }\end{array}$ \\
\hline Ixabepilone & Subacute or chronic & Onset is acute or subacute \\
\hline Eribulin & Subacute or chronic & $\begin{array}{l}\text { Quick recovery in mild cases } \\
\text { Long-term data needed }\end{array}$ \\
\hline
\end{tabular}

mary involved site is the dorsal root ganglion, the peripheral nerve may be involved. Patients complain of paresthesias and some degree of motor loss. Temperature sensation is spared, although proprioception and reflexes are lost. Autonomic neuropathy is encountered less often than sensory and motor neuropathies. The onset can be subacute or chronic; usually, NP and NCP occur months later (3-6 months), or sometimes the symptoms become evident after the chemotherapy cycles have finished. ${ }^{54}$ Although cisplatin neurotoxicity is dose-related, NP is more common with increasing dosages, and there is substantial variability among individuals for sensitivity. ${ }^{24}$ Cisplatin-associated electrolyte imbalance can contribute to the neurotoxic process. On pathological examination, both demyelination and axonal loss can be evident. Symptoms may continue with decreasing intensity after months or even years. ${ }^{24,25,33}$ Although there are some data about the prevention of cisplatin neurotoxicity with utilization of vitamin $\mathrm{E}$ and amifostine, a Cochrane meta-analysis could not find any beneficial effects of preventive strategies. ${ }^{55}$

Oxaliplatin is a new type of platinum-class drug. It is effective mainly in colon cancer as well as in other gastrointestinal malignancies. It has a different NP profile than cisplatin. It can cause acute dysesthesia within hours, even during infusion and/or painful abdominal pain. Similar to cisplatin, it can cause cumulative sensory NP in a chronic setting. The acute symptomatology consists of painful 
muscle cramps, paresthesias in distal extremities and the perioral region and rarely priapism. These symptoms can be aggravated by cold exposure. Acute toxicity is believed to be the result of calcium chelation, leading to activation of low-calcium voltage-gated channels in peripheral nerves. ${ }^{56}$ The dose-limiting neurotoxicity is the late onset, cumulative, sensory, symmetric distal axonal neuropathy. There is no motor involvement. Similar to cisplatin, oxaliplatin forms deoxyribonucleic acid adducts, especially in the neurons of dorsal root ganglia. ${ }^{57}$ The main problem with oxaliplatin NP is that it also affects proprioception and can cause urinary retention. Therefore, quality of life is further decreased. ${ }^{25,33}$ In contrast to cisplatin, oxaliplatin neurotoxicity may be reversible after discontinuation of treatment.

Gemcitabine is a purine analog used for treatment of pancreatic cancer, lung cancer, and bladder cancer. Neuropathies in a wide spectrum can be encountered with gemcitabine therapy, from mild paresthesias to severe peripheral and autonomic neuropathies. ${ }^{58}$

Taxanes as microtubule inhibitors are another major group of drugs responsible for NCP, but their role in oncology practice is also incontrovertible. They are used mainly in breast cancer, lung cancer, and ovarian neoplasms. They give patients the chance to survive longer and remain mostly disease-free. However, NP and NCP significantly decrease their quality of life. In general, taxanes affect sensory neurons related to vibration sensation and proprioception. The symptomatology of neuropathy associated with taxanes includes peripheral burning-like sensations and numbness, paclitaxel-associated acute pain syndrome (which is characterized by arthralgias, myalgias, and numbness that begins within 1-2 days following treatment and lasts 4-5 days), motor neuropathies, and rarely autonomic neuropathy. ${ }^{59,60}$ Neurotoxicity is dose-related. Coexisting neurotoxic diseases and chemotherapeutic agents that are used in combination are also important in the NCP process. Taxane and platinum compound neurotoxicity is synergistic. Both taxanes and platinum-group drugs can cause axonopathy and neuronopathy (damage to neurons in dorsal root ganglia). The difference between them is important for NP prognosis. Neuronopathy is accepted as a more progressive, irreversible process compared to axonopathy. ${ }^{61}$ Docetaxel causes both sensory and motor neuropathy, though these are less frequent. Nab-paclitaxel is a new member of the taxane group of drugs for which clinical experience is low. There are studies showing that its neurotoxicity profile is similar to docetaxel both in prevalence and intensity. ${ }^{62}$ The acute painful neuropathy syndrome can be observed more frequently with nab-paclitaxel. ${ }^{63}$ Cabazitaxel is another new drug that is approved for the treatment of castration-resistant prostate cancer. NP was reported as $13 \%-17 \%$, with severe NP less frequent. ${ }^{64}$

Vinca alkaloids are effective anticancer agents due to their antimicrotubule activities. Vincristine is the most neurotoxic drug of the available drugs in the vinca alkaloid class. Both sensory and motor neuropathies can be encountered. It can cause NCP, painful paresthesias in hands and feet, and muscle cramps. The onset of NP can be acute or subacute, and NP can last even after discontinuation of the drug. ${ }^{65}$ Comorbid neuropathic diseases and concurrent use of hematopoietic colony-stimulating factors can increase the NP and NCP. ${ }^{66}$ It is important to note that autonomic neuropathies can be encountered with vincristine. Abdominal pain, constipation, and even paralytic ileus may develop. Impotence, atonic bladder, and postural hypotension may develop, but are far less common. ${ }^{67}$ Vincristine can cause focal cranial mononeuropathies, as seen in oculomotor neuropathy, or in the optic nerve and facial nerve. ${ }^{68}$ Patients with mild neuropathy may continue with standard doses of treatment, but if symptoms increase in intensity, the dose should be reduced or the drug must be totally canceled from the regimen. The recovery process takes more time. There are data suggesting glutamic acid use for prophylaxis of vincristine NP, but the evidence level is not strong enough to apply in clinical practice. ${ }^{69}$ Although there is a risk of NCP with vinblastine and vinorelbine, the severity is less than compared to vincristine.

Ixabepilone (an epothilone-class microtubule inhibitor) and eribulin (derived from a marine sponge) are two new drugs with antimicrotubule inhibitor effects. ${ }^{70,71}$ Both of them were reported to be associated with NP. Ixabepilone may cause autonomic NP in addition to sensory NP. Grade 3-4 NP with ixabepilone occurs in 6\%-24\% of cases, and dose reductions are advised in such cases. ${ }^{70}$

Thalidomide is a potent antiangiogenic agent that is used especially for multiple myeloma. It has a cumulative, dosedependent NP side effect. ${ }^{72}$ The neuropathy of thalidomide presents as symmetrical distal sensory NP and motor NP. The underlying pathology is suggested to be toxic axonopathy. ${ }^{73}$ The dose-limiting toxicity is the NP, but NP is only partially reversible, even after the discontinuation of therapy. Autonomic NP is also common, especially in senior adults. This can complicate the treatment process of myeloma in the elderly, since NP may present as bradycardia and also constipation and impotence. ${ }^{74}$ Lenalidomide is a second-generation drug with more potency but less neurotoxicity. ${ }^{75}$

Bortezomib is a member of a new class of chemotherapeutics called proteasome inhibitors. It is a reversible $20 \mathrm{~S}$ 
proteasome-complex inhibitor, acting by disrupting the cell-signaling process, leading to cell-cycle arrest, apoptosis, and inhibition of angiogenesis. In 2003, it was approved by the US Food and Drug Administration for refractory multiple myeloma. ${ }^{76}$ Later, bortezomib gained importance in the treatment of early stages of myeloma and other hematologic malignancies (ie, mantle-cell lymphoma). ${ }^{77}$ There are ongoing investigations in the treatment of solid malignancies with bortezomib in combination with other chemotherapeutic agents. ${ }^{78,79}$ Peripheral neuropathy is a dose-limiting toxicity of bortezomib, usually presenting as length-dependent axonal neuropathy distributed in a stocking-and-glove pattern. ${ }^{80}$ In addition, patients may develop demyelinating polyneuropathy and sensory ganglionopathy. The effects on neurons or axons are dose-dependent, usually evident with the first cycle of chemotherapy, and increase in severity as treatment continues. ${ }^{80,81}$ Reversibility of neuropathy has been shown to be up to $80 \%$ in various trials. ${ }^{78,80-82}$ Ixazomib, marizomib, and carfilzomib were developed as irreversible proteasome inhibitors. ${ }^{83}$ In clinical trials, they are associated with less neuropathy risk than observed with bortezomib. ${ }^{83,84}$

\section{Clinical assessment of cancer patients with neuropathic pain}

The diverse heterogeneity of pain syndromes in cancer patients makes them also difficult to assess, score, and handle. Therefore, a detailed patient history and a meticulous clinical examination are necessary steps to confirm the diagnosis of NP and NCP. Past history with particular attention to comorbidities and family history of any neurological diseases are important in terms of the risk of developing NP. Medication history should always be kept in mind, as drug interactions and cumulative neurotoxicities are common in NCP treatment. It is important to assess the severity of pain by a painassessment scale (visual analog scale, brief pain inventory ${ }^{85}$ or its short form [BPI-SF], memorial pain assessment ${ }^{86}$ ). Particular attention should be given to location, radiation, frequency, and aggravating factors of pain. Standardized screening tools, such as the NP questionnaire, PainDetect, and ID-Pain have been developed. ${ }^{87}$ Although these screening tools cannot identify $10 \%-20 \%$ of patients with NCP, they offer guidance to clinicians. ${ }^{88}$ Moreover, the impact of pain on patients' daily living, functional status, emotions, social functions, and sleep should be assessed.

A bedside examination should include the examination of components that include touch, pinprick, pressure, temperature, vibration sensation, and temporal summation. ${ }^{10}$ Touch can be assessed by gently applying cotton wool to the skin, pinprick sensation by the response to sharp pinprick stimuli, deep pain by gentle pressure on muscle and joints, and cold and heat sensation by measuring the response to a thermal stimulus (eg, by burettes filled with hot and ice-cold water). Vibration can be assessed via a tuning fork. Abnormal temporal summation is the clinical presentation of neuronal activity after repetitive noxious stimuli, which can be evoked by mechanical and thermal stimuli. There are several different electrophysiological methods to quantify neurologic dysfunction that can help to identify patients with NP and NCP. Nerve-conduction and electromyography studies, provocative nerve testing, functional brain imaging, and skin biopsy for nerve-ending pathologies are tests that are beneficial. ${ }^{89,90}$ However, none of these modalities has been validated in cancer patients, and they are not in widespread use. Their use needs physician expertise and special resources, and they are not practical to use in everyday practice. ${ }^{90}$

\section{Pharmacologic treatment of neuropathic cancer pain}

The first approach for a patient at risk of NP is the prevention of NP. However, there is no strong evidence in favor of agents that are used for prevention of NCP. ${ }^{36,89,91}$ Since the pathophysiology of NCP is complex, long-term management of NCP is challenging for physicians dealing with cancer patients. ${ }^{5,32}$

Decades after the publication of the World Health Organization (WHO) analgesic ladder, cancer pain is still a burdensome symptom for patients. NCP is even more complicated, since the pain mechanisms are complex and integrated with one another. Today, many of the guidelines accept data extrapolated from nononcological pain studies as evidence for treatment of oncological patients with pain and NCP. ${ }^{9,88,92}$ European and NCCN guidelines follow the revised WHO orders to treat pain in cancer. The WHO recommends starting the treatment in a stepwise manner and following the patient for symptom relief and side effects..$^{93,94}$ There are opioid and nonopioid treatment options for pain relief in cancer patients. In the following section, pharmacological treatment options will be briefly discussed, and detailed information of adjuvant analgesics will be provided.

Mild cancer pain (eg, pain-intensity rating as 1-3) is treated with nonopioid analgesics. Paracetamol and/or nonsteroidal anti-inflammatory drugs (NSAIDs) are the drugs of choice. ${ }^{9,92}$ They are beneficial for bone and soft-tissue pain. Hepatic toxicity should be kept in mind for paracetamol, while cardiac, gastric, and renal side effects and thrombocytopenia/platelet dysfunction are important considerations 
in the use of NSAIDs. There is no evidence to support a particular NSAID over any other in terms of safety and efficacy. ${ }^{95}$ Even if the pain is not alleviated with NSAIDs, these drugs should be continued with opioids. ${ }^{96}$

Opioids are the mainstay of therapy in cancer patients. Treatment of pain beyond mild intensity needs the implementation of opioids to treatment. Weak or short-acting opioids (eg, codeine, dihydrocodeine, and dextropropoxyphene), drugs with mixed effects (tramadol, tapentadol), and partial opioid agonists (transdermal buprenorphine) are advised if the result with nonopioid analgesics was not satisfactory., 92 There are some controversies about this approach. To start, there is not enough evidence that adding a short-acting opioid is better than a nonopioid treatment. ${ }^{92}$ Second, the use of low-dose strong opioids or low-dose morphine can be more effective than short-acting opioids. ${ }^{9,97}$ Codeine is a prodrug, and has to be changed into morphine-6-glucorinide in order to show its effect. Due to genetic polymorphism in the metabolism of this drug, it may not be effective in $10 \%-30 \%$ of the population. ${ }^{98}$ Regarding drugs used for moderate-intensity pain, tramadol deserves special interest. It is a centrally acting drug, with both opioid activity and monoaminergic properties. Tramadol has good bioavailability and has been proven effective in the treatment of strong pain and NP. ${ }^{99}$ The risk of serotonin syndrome prevents its use in combination with monoamine-oxidase inhibitors. The side-effect profile is similar to other opioids, except constipation incidence is less. Even at maximum doses, its effects are less than other opioids. ${ }^{9}$ Tapentadol is a $\mu$-opioid analgesic with a norepinephrine reuptake-inhibitory effect. ${ }^{100}$ Although most of the data about the efficacy of tapentadol comes from nononcological trials, it has been shown to have a moderate analgesic effect. ${ }^{100}$ The gastrointestinal side effects of tapentadol may be lessened..$^{9}$ Once the pain cannot be modified any further, rather than combining short-acting or weak opioids with each another, it is recommended that longer-acting and strong opioids be used. In each step of pain treatment, coanalgesics may be added to treatment, as will be discussed further in detail.

The strong opioids are used in severe pain syndromes alone or in combination with nonopioid analgesics and/or coanalgesics. These drugs include morphine, hydromorphone, methadone, and fentanyl. Pethidine was used for this intent, but is no longer recommended, because of the accumulation of a neurotoxic metabolite. ${ }^{8}$

Morphine, oxycodone, and hydromorphone are effective drugs for pain management. Each of these could be the first choice of drug in personalized treatment of cancer pain.
Morphine used to be the standard choice for pain treatment in cancer patients for decades. It is available in a wide variety of formulations, and can be used via oral, rectal, and intravenous routes. There is a risk of active metabolite accumulation in patients with renal failure. ${ }^{101}$ Oxycodone is a synthetic opioid that can be used orally or parenterally. It has no active metabolite, and is therefore safe to use in comorbid kidney disorders. Additionally, it has clinical efficiency in NCP and visceral pain. ${ }^{11}$ Naloxone is a peripheral $\mu$-receptor antagonist used in combination with oxycodone to overcome constipation, one of the most common and refractory side effect of opioids. ${ }^{102}$ Safety and efficacy of this combination was shown in a recent trial. ${ }^{103}$ Hydromorphone is a semisynthetic opioid with three- to fivefold the potency of morphine. Similar to morphine, it has an active metabolite that is dialyzable, allowing its use in patients on dialysis.

Transdermal fentanyl is a potent, effective alternative to oral, slow-release opioids that is preferred by oncologic patients incrementally. The bioavailability depends on absorbance through the skin, since cachexia can reduce its efficacy. ${ }^{104}$ Transdermal fentanyl should not be used as a first line drug in patients, for whom their pain may be clinically stabilized with other opioids. It is typically the treatment of choice when a patient has difficulty in swallowing or poor compliance, and it should be used in caution in patients with risk of sedation.

Methadone is an NMDA antagonist. Although it has a bad reputation for being used in drug abuse, it is a useful drug when applied by experienced pain physicians. Its unpredictable half-life and risk of accumulation and toxicity prevents the use of methadone in everyday practice. ${ }^{8}$

One of the main barriers to effective pain management for oncologic patients is the fear of drug addiction and/or common and worrisome side effects. Although most of the mentioned opioid drugs proved to be addictive in an otherwise painless individual, that fear was shown to be unfounded in oncologic patients suffering from moderate-to-severe pain. ${ }^{105}$ The classical side effects of opioids vary, and are listed in Table 7. Constipation is the most common continuing adverse effect, and is related to blockage of peripheral $\mu$-receptors. Laxatives

Table 7 Adverse effects of opioids

\begin{tabular}{ll}
\hline Emesis & Bronchoconstriction \\
Constipation & Respiratory depression \\
Sedation & Delirium \\
Cough suppression & Seizures \\
Sedation & Noncardiogenic pulmonary edema \\
Pruritus & Immunodeficiency \\
Dry mouth & Allodynia \\
\hline
\end{tabular}


should be applied with the first few days of opioid institution. Stimulating laxatives are necessary to prevent and overcome the constipation. Naloxone in combination with oxycodone is effective in this setting. Mild drowsiness is also common, but generally dissipates or decreases in severity with the development of tolerance. If treatment is prolonged, an opioid switch should be considered. Emesis is a side effect of opioids to which tolerance develops within first few days of opioid initiation. Emesis can be managed with antiemetics. If the emesis continues, a change of route of administration can help or an opioid switch can be considered. ${ }^{9}$ Opioid-dose reduction and combination with coanalgesics may improve the adverse effects. Guidelines recommend use of the opioids with nonopioid analgesics and adjuvant analgesic or coanalgesics. ${ }^{9,88,92}$ The term "coanalgesic" means that a drug is intended to play another role in the pharmaceutical market but potentially useful when added to opioids in pain management. ${ }^{106}$

Coanalgesics should be utilized when opioid response is poor or no more titration of the dose is possible because of inevitable side effects. The addition of a second analgesic makes the control of both the pain and side effects easier. Coanalgesics can be used at every step of the WHO ladder, but are generally added by physicians when difficulties occur during pain management concurrent with increased severity or side effects.

Management of NP is a challenge. Control of NCP usually requires higher doses of opioids then what is tolerable, thus the need for adjuvant analgesics or coanalgesics. The coanalgesic drug group include gabapentinoids (gabapentin, pregabalin), antidepressants (TCAs, duloxetine, and venlafaxine), corticosteroids, bisphosphonates, NMDA antagonists, and cannabinoids. ${ }^{9,92,107,108}$ Although it is criticized frequently, the most common approach to compare clinical trials is to compare the number-needed-to-treat and number-needed-to-harm values of drugs. These coanalgesic drugs have number-needed-to-treat values of 3-5, which are within the therapeutic interval. ${ }^{88,109}$ In the following section, coanalgesic drugs will be described in detail.

\section{Coanalgesics}

\section{Antidepressants}

\section{Tricyclic antidepressants}

TCAs are well-known drugs that inhibit norepinephrine and serotonin reuptake in the CNS, modulating sodium channels and augmenting dorsal root ganglion blockage by the inhibition of NMDA receptors. ${ }^{11,110}$ The efficacy of TCAs is established mainly in PHN. ${ }^{111,112}$ Antidepressive effects create a double hit to NP mechanism, since pain perception is highly increased with depression. TCAs are thought to have analgesic effects at dosages lower than required for depression. Drug toxicity can be dose-limiting for TCA, since they are strongly anticholinergic drugs. The most common side effects are the result of their anticholinergic activity, which are dry mouth, constipation, blurred vision, cognitive impairment, and orthostatic hypotension. ${ }^{11}$ Therefore, they should be started cautiously in patients with cardiac problems and especially in the elderly. A baseline electrocardiogram should be obtained and repeated as necessary. There is large pharmacokinetic variability in the metabolism of this class of drugs, so personalized treatment is important. Imipramine, desipramine, and nortriptyline are accepted as safer than amitriptyline. ${ }^{11}$ Further data on dosage of analgesics, coanalgesics, and warnings are summarized in Table 8.

\section{Other antidepressants}

The analgesic effects of selective serotonin-reuptake inhibitors are not well established, as there is not enough clinical evidence. ${ }^{9,109}$ The selective serotonin-norepinephrine inhibitors (SNRIs) venlafaxine and duloxetine are the drugs of choice in NCP, although the main evidence of their effectiveness in NP was established in studies on diabetic neuropathy. Venlafaxine is the first SNRI to be effective in NP. In a welldesigned study comparing venlafaxine and imipramine, both were found to be equally effective. ${ }^{113}$ The dosage is important, since lower dosages $(<75 \mathrm{mg})$ are ineffective in NCP, and higher doses are required $(>150 \mathrm{mg}) .{ }^{114}$ Acute oxaliplatin toxicity can be successfully treated with venlafaxine. ${ }^{115}$ Elevation of blood pressure is a risk during venlafaxine treatment, and regular monitoring is necessary. The main side effects are gastrointestinal disturbances, but rarely result in drug discontinuation. Venlafaxine dose should be reduced in severe hepatic and renal insufficiency. In comparison with duloxetine, venlafaxine was found to be more effective but with more side effects. ${ }^{116}$

Duloxetine is a relatively new agent in the SNRI family. It has been found to be more effective than placebo. ${ }^{117,118}$ Dose titration of duloxetine should be done in no less than 2 weeks, as the effect of drug begins in that period. ${ }^{119}$ It is a better agent, since no cardiotoxicity has been reported yet. Doses of 60-120 mg are efficient, but lower doses are not. ${ }^{120}$ Venlafaxine has been found to be effective in postmastectomy pain syndrome after breast cancer surgery. ${ }^{121}$ In respect to CINP, duloxetine is more effective than placebo, and can be considered in first-line therapy. ${ }^{122}$

Bupropion is an antidepressant with norepinephrine and dopamine reuptake-inhibitory effect. It acts both centrally 


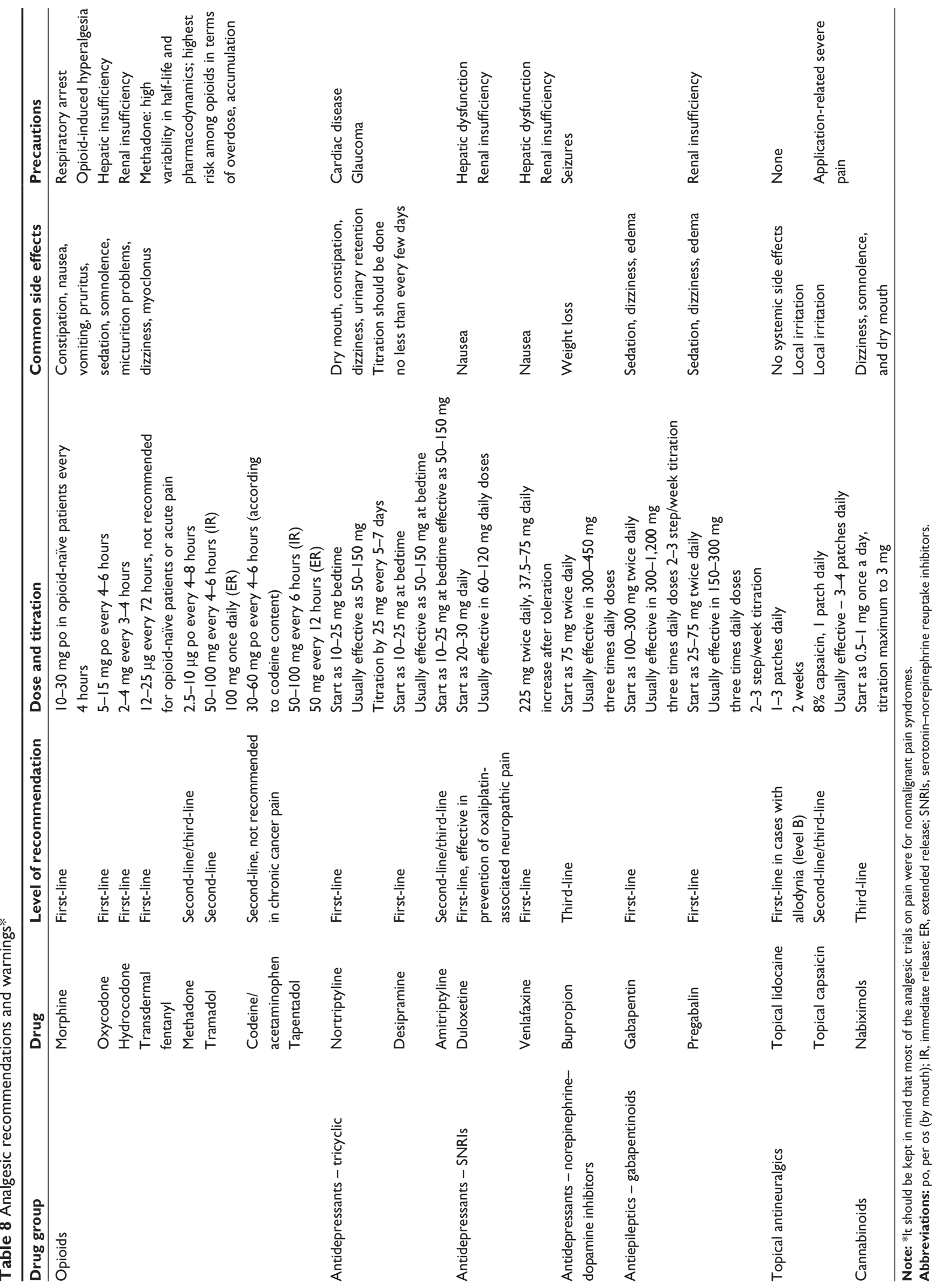


and peripherally. ${ }^{119}$ Bupropion is distinguished from other antidepressants in its efficacy for stimulation in the CNS. It can be used as a first-line drug in patients who are suffering from fatigue or somnolence in addition to NCP. This drug should be used with caution in patients prone to seizures. Bupropion can have a negative effect on cancer patients who are already prone to cancer cachexia. ${ }^{10,123,124}$

\section{Antiepileptic drugs - gabapentinoids}

Nowadays, physicians dealing with pain focus on diseasemodifying therapies rather than simply modifying the symptoms. One of the main pathophysiologic mechanisms of NP is hyperexcitability. Understanding of the importance of hyperexcitability enabled the use of antiepileptic drugs in NCP. The main antiepileptic drugs employed in NCP are gabapentinoids (gabapentin and pregabalin). They act by inhibiting calcium channels on terminals of afferent nociceptors. Both drugs have established efficacy, mainly in diabetic NP and PHN, but pregabalin trials are more focused on central mechanisms.

\section{Gabapentin}

Dorsal root ganglia have a central role in NP, since the downregulation of their action results in the inhibition of transduction of spontaneous peripheral nociceptive signals. $\gamma$-Aminobutyric acid is an important neurotransmitter of dorsal root ganglia. Gabapentin acts by decreasing the release of glutamate, norepinephrine, and substance $\mathrm{P}$, with ligands on the $\alpha_{2} \delta$ subunit of voltage-gated calcium channels. ${ }^{10,27}$ Gabapentin is effective in NCP and specific CINP. ${ }^{125-128}$ Clinical trial data comparing gabapentin and TCA showed equivocal results. ${ }^{129}$ It diminishes both tumor- and chemotherapyinduced pain, as well as iatrogenic hot flashes and nausea/ vomiting and pain syndromes associated with mucositis. ${ }^{130}$ Gabapentin needs several weeks before achieving a steadystate plasma level; therefore, its onset of action is late. One of the main advantages of gabapentin is its effective combination with opiods in the treatment of NCP, especially for allodynia, which is a less responsive type of pain to other combinations of drugs. ${ }^{125,128,131}$ The most common side effects include dizziness and somnolence, peripheral edema, weight gain, asthenia, and dry mouth.

\section{Pregabalin}

Pregabalin has the same mode of action as gabapentin, but has a greater affinity for voltage-gated calcium channels. Its onset of action is faster than gabapentin. Pregabalin improves sleep, quality of life, and daily living abilities to the same extent as gabapentin. ${ }^{132}$ Recent trials in NCP showed that pregabalin use is effective in combination with opioids and enables the downtitration of the opioid dose. Somnolence and dizziness are the dose-limiting side effects.

\section{Other antiepileptics}

Lamotrigine was thought to be effective, but the results of a new Cochrane review showed that in the presence of highly proven therapies like gabapentinoids and TCAs, lamotrigine is not a beneficial drug for NP. ${ }^{133}$ Second-generation anticonvulsants (levetiracetam, oxcarbazepine, tiagabine, topiramate) are used in seizure disorders frequently, since their side effects are reduced and drug interactions are fewer. Carbamazepine and oxcarbazepine have been used in trigeminal neuralgia, but recent studies do not advise their use in PHN or NCP. ${ }^{43,134}$

\section{NMDA antagonists: ketamine, dextromethorphan, amantadine, magnesium}

NMDA is an excitatory neurotransmitter. Its role is significant in chronic NP, since the balance is disrupted between excitation and inhibition. Ketamine is a potent NMDA antagonist among the family, and acts by inhibiting dorsal root ganglia. It is also known to have anti-inflammatory effects; theoretically, it should be a good agent for NCP relief. Its analgesic effect is at subanesthetic doses. However, at lower doses, its serious side effects limit its use. ${ }^{135,136}$ In two recent prospective trials, it was not found to be effective as an adjunct analgesic to opioids, although some controversies exist. ${ }^{137-139}$ The use of ketamine should be reserved for resistant NCP patients, and only applied by pain professionals. There are insufficient data regarding the efficacy and safety of other NMDA antagonists.

Magnesium is an economical and effective approach for the prevention of CINP of oxaliplatin. ${ }^{140}$ Especially when infused with calcium, it may decrease resulting numbness, cramps, and difficulty in swallowing. In a recent review, magnesium and calcium infusions were found to be effective in the prevention of CINP. ${ }^{122}$

\section{Topical antineuralgics: lidocaine, capsaicin}

Topical analgesia has the potential to be a useful adjunct to treatment of NCP with opioids and/or coanalgesics. The main two groups of drugs that are in use for NP are lidocaine and capsaicin. ${ }^{141,142}$

Lidocaine relieves pain through nonspecific blocking of sodium channels on afferent fibers. Its use is convenient, since no systemic absorption occurs, and only local side 
effects are seen. Topical lidocaine is available as a 5\% patch or gel. Topical lidocaine is effective in peripheral neuropathy syndromes with allodynia. ${ }^{143-145}$ It has been used in CINP and postsurgery in breast cancer patients. ${ }^{109}$ Topical lidocaine treatment achieved a sufficient level of analgesia in 50\% of patients in a 2-month to 4 year-period. ${ }^{124}$ Although absorption is minimal, it should not be used with oral class I antiarrhythmic drugs.

Capsaicin is a natural product found in chili peppers, and is a special ligand of transient receptor potential vanilloid 1 (TRPV1). When capsaicin binds to TRPV1 receptors, calcium influx occurs on heat-receptor membranes and leads to desensitization, and in the long term results in depletion of substance P. ${ }^{146}$ There are topical low-moderate dose $(0.075 \%-0.04 \%)$ capsaicin preparations, but insufficient data and inconsistent results. ${ }^{146}$ The high-dose patch contains $8 \%$ capsaicin. The benefits of high-dose preparations have been shown in NP and HIV neuropathy. ${ }^{147}$ Common side effects include local erythema, edema, itching, and initial pain necessitating opioids. High blood pressure can be the result of intense pain associated with the drug, and it should be monitored closely. ${ }^{109}$

\section{Other drugs: tapentadol, cannabinoids, vitamins}

Tapentadol is a new synthetic opioid drug that has an inhibitory effect both on $\mu$-opioid receptors and central norepinephrine uptake. ${ }^{148}$ It has a lower affinity for $\mu$-receptors than strong opioids have. In Phase II and III studies, the efficacy of tapentadol has been proved in comparison to placebo and oxycodone. ${ }^{149,150}$ Regarding safety, it has been hypothesized that due to low $\mu$-receptor affinity, the drug could have fewer opioid side effects. In 2012, Merker et al published a meta-analysis of reported adverse effects in tapentadol in randomized clinical trials. ${ }^{151}$ Typical gastrointestinal side effects (emesis and constipation) were found to be significantly lower, although xerostomia was higher in the tapentadol-received group of patients (relative risk 1.79, 95\% confidence interval 1.40-2.29). Those randomized controlled trials were all nononcological trials. Mercadante et al conducted a tapentadol trial in opioid-naïve cancer patients. At the end of the study, patients all had a response, with decreases in pain intensity and with no increment of adverse effects. ${ }^{100}$ Although the evidence regarding tapentadol is not conclusive yet, its use holds promise.

Cannabinoids are compounds that are effective for pain relief, appetite enhancement, and suppression of emesis via acting on endogenous cannabinoid receptors by imitation of endogenous ligands. ${ }^{152,153}$ There are two types of endogenous cannabinoid receptors $(\mathrm{CBs})$ : $\mathrm{CB}_{1}$ is active on the $\mathrm{CNS}$, and $\mathrm{CB}_{2}$ is prevalent in the periphery. $\delta$-9-Tetrahydrocannabinol is a partial $\mathrm{CB}_{1}$ and $\mathrm{CB}_{2}$ agonist. The therapeutic potential of cannabinoids has been investigated in chronic pain extensively. In animal models, cannabinoids and opioids were shown to be synergistically effective. ${ }^{154,155}$ The oromucosal cannabinoid form is effective in NP associated with multiple sclerosis and peripheral nononcological NP..$^{11,88,110}$ In 2012, a novel cannabinoid agent, nabiximols, was studied in a double-blind study of cancer patients. ${ }^{152}$ Although the effect on pain intensity was better, the effect size was small, and the incidence of adverse effects and dropout rate were high. Despite the promising results of previous studies, the use of cannabinoids in NCP is not established yet.

Mainstream "natural living" is a popular topic regarding the prevention and treatment of cancer and its related adverse effects. Many studies have examined the roles of vitamin E, vitamin $\mathrm{C}$ and $\alpha$-lipoic acid. ${ }^{55,122,156,157}$ There are controversies concerning the results of those studies: although a particular decrease in incidence of NP with the use of vitamin E was shown, ${ }^{122,158}$ the results could not be replicated in a large Phase III randomized controlled trial. ${ }^{159}$

\section{Combination therapy}

The WHO recommends managing pain in a stepwise manner to achieve better pain relief with fewer side effects. However, the efficacy of a single agent is limited, due to both complicated pain mechanisms and dose-limiting adverse effects. There have been many efforts to develop better drugs or favorable combinations of available drugs. Berger et al showed that nearly half of NP patients receive more than two analgesic drugs concomitantly. ${ }^{160}$

Ideally, combination treatment should focus on maximum efficiency with less toxicity and minimum drug interaction, and synergistically different mechanisms of action. ${ }^{161}$ Nowadays, although there are scarce data, the most common prescribed combinations of analgesics are fixed-dose combinations of NSAID + opioids, NSAID + tramadol, antidepressants + anticonvulsants, and antidepressants + opioids. ${ }^{161}$

Chaparro et al analyzed 21 randomized controlled trials (gabapentin + nortriptyline, opioid + TCA, fluphenazine + TCA, opioid + gabapentin/pregabalin) in a Cochrane review. ${ }^{162}$ They concluded that many good-quality trials showed the superiority of combination therapy to monotherapy, but a particular combination was not specified. They emphasized the intensification of adverse effects with combinations, particularly sedation. After this Cochrane 
review, a few promising studies have been published. The combination of pregabalin and oxycodone has been shown to be operative and safe in previous studies. ${ }^{110,163,164}$ Garassino et al conducted a study to investigate the practical dose escalation of a pregabalin-oxycodone combination. ${ }^{165}$ They showed that the pregabalin dose can be escalated safely, in contrast to recent applications in clinical practice. They showed that if the pregabalin dose is increased slowly, higher doses can be achieved. In 2013, Nishihara et al investigated the impact of mirtazapine on pain in combination with pregabalin in a refractory NP syndrome. ${ }^{166}$ Although mirtazapine did not relieve pain when used alone, based on the results of this study, the combination had additive/synergistic effects compared to a doubled dose of pregabalin. One of the interesting points of this study was that the onset of action of the combination was as early as 1 week. A third study from Lazzari et al showed that the addition of low-dose oxycodone-naloxone to the gabapentin-pregabalin combination treated patients successfully, with fewer gastrointestinal side effects. ${ }^{167}$

\section{Nonpharmacological therapy of neuropathic cancer pain}

Every cancer patient is unique, with individual presentations of pain. NCP is more complicated than other pain syndromes. It is not always possible to manage pain appropriately and sufficiently by means of drugs, NCP remains refractory, and more techniques or approaches are needed. Nonpharmacological therapies are needed for NCP when drug effects are not adequate or not applicable. The primary nonpharmacological therapies are the treatment approaches targeting the etiology of pain (eg, radiotherapy), invasive symptomatic therapies (eg, nerve blocks), and noninvasive symptomatic therapies (Table 9). Some of these approaches are considered specifically for refractory pain, and some of them are suitable as adjuncts to conventional treatment. Celiac plexus block and splanchnic neurolysis are the most accepted interventions. ${ }^{168-170}$ There are surgical ablative methods, such as cordotomy, myelotomy, and dorsal root entry-zone lesioning. ${ }^{171}$ There have been few studies conducted to prove the efficacy of interventional approaches, since it is difficult and unethical to find and apply a sham procedure. Palliative radiotherapy to a specific region (abdominal) or bony metastasis is beneficial. In a recent trial, intrathecal infusion therapy was not found to be beneficial. ${ }^{172}$ Cognitive-behavioral interventions and mind-body therapies (relaxation, imagery, hypnosis, and biofeedback) may have a role to play. ${ }^{173}$ It is hypothesized that the mechanism of NCP intersects with the pain-relieving mechanism of acupuncture. However, in a recent meta-analysis, Garcia et al emphasized that the results of acupuncture trials in NCP were questionable. ${ }^{174}$ Little evidence exists about the effects of psychological therapies. However, cancer pain is multidimensional, and patients may perceive some benefit from physical, rehabilitative, and integrative therapies as well.

\section{Future aspects - conclusion and perspectives}

According to the new definition of the IASP, neuropathic pain is defined as "pain arising as a direct consequence of a lesion or disease affecting the somatosensory system".? Although this definition narrows and simplifies NP for physicians, NCP is still underreported, underdiagnosed, and not treated efficiently. Therefore, NCP remains an open area where new treatment approaches are needed urgently. Several treatment options have been studied in randomized controlled trials $^{179-181}$ to shift the paradigm of NP treatment towards more targeted and multimodal agents, and may contribute to treatment of NCP in the future.

Recently, there has been a dramatic increase in efforts to reveal a genetic contribution to the mechanism of perception of pain and a genetic impact on the efficacy and safety of drugs. Genetic polymorphisms that are linked to alterations of pain perception are generally single-nucleotide polymorphisms of genes coding for receptors, ion channels, transcription factors, cytokines, and enzymes. ${ }^{175}$ Personal variations in opioid requirements and toxicity have been investigated heavily. The strongest link was found to be the p450 cytochrome 2D6 gene variations. ${ }^{176,177}$ However, there are associations of

Table 9 Nonpharmacological treatment approaches in neuropathic pain

\begin{tabular}{|c|c|c|c|c|}
\hline $\begin{array}{l}\text { Interventional } \\
\text { approaches }\end{array}$ & $\begin{array}{l}\text { Rehabilitative } \\
\text { approaches }\end{array}$ & Psychological approaches & Neurostimulation & $\begin{array}{l}\text { Integrative/alternative } \\
\text { approaches }\end{array}$ \\
\hline Neural blockade - neurolysis & Exercise & Cognitive behavioral therapy & Transcutaneous & Acupuncture/acupressure \\
\hline $\begin{array}{l}\text { Implant therapy - intrathecal } \\
\text { drug delivery }\end{array}$ & Hydrotherapy & $\begin{array}{l}\text { Relaxation therapy, guided imagery, } \\
\text { other types of stress management }\end{array}$ & Transcranial & Massage \\
\hline Injection therapies & & Psychoeducational interventions & Implanted & \\
\hline Radiotherapy-ablation therapies & & & & \\
\hline
\end{tabular}


the catechol- $O$-methyl transferase, melonocortin- 1 receptor, and $\mu-1$ opioid receptor genes in the response to analgesics. ${ }^{175,178}$ Another contribution to pain treatment by genetic mechanisms is targeted drug delivery to the PNS using gene therapy. Preclinical studies have been done with nonreplicating virus vectors injected into skin to transduce neurons in the dorsal root ganglion in animal models with neuropathic pain and NCP. Wolfe et al conducted a Phase I trial of gene therapy with herpes simplex virus vectors expressing human preproenkephalin. ${ }^{179}$ The primary outcome was safety; pain modulatory effects were shown in moderate-higher doses. A Phase II trial is now underway. In the future, better outcomes will be achieved by the application of further understanding of genetics and molecular biology of pain.

Animals have evolutionary mechanisms for defense and hunting via assorted small molecules. These have attracted the attention of investigators for a long time. One of these is cobratoxin, a nicotinic acetylcholine receptor antagonist, which is analgesic at lower doses, although lethal in higher doses. This molecule in combination with opioids and NSAIDs was investigated in 230 cancer patients with severe pain, and was found to be superior to NSAIDs or analgesic monotherapy. ${ }^{180}$ Cone snails have natural substances called conopeptides, and one of these is ziconotide, which was found to be effective in chronic pain. ${ }^{181-184}$ It acts via blocking N-type voltage-sensitive calcium channels in the dorsal horn. ${ }^{185}$ In 2004, the US Food and Drug Administration approved the intrathecal application of ziconotide in refractory pain conditions. Tetrodotoxin is a sodium-channel antagonist derived from puffer fish. In animal models and in cancer clinical trials, it was found to be beneficial in pain relief. ${ }^{186-190}$ In the future, results of these and further studies will have had an impact on pain-management strategies.

CINP is detrimental, besides decreasing the quality of life of cancer patients it interferes with the treatment process and may lead to drug cessations. There is emerging information indicating that proinflammatory cytokines are important in the pathogenesis of CINP. ${ }^{191,192}$ Macrophages are accused of being involved in the neuroinflammatory process of the axons and neurons of dorsal root ganglion (DRG) in CINP. In response to chemotherapy-induced hypoxic injury, macrophages secrete or organize other inflammatory cells to product cytokines (tumor necrosis factor- $\alpha$, interleukin [IL]-1 $\beta$, IL-6, IL-8), chemokines (CCL2, CXC family), growth factors, and inflammatory mediators, such as bradykinin, prostaglandins, serotonin, and nitric oxide. ${ }^{178,191,193}$ These small molecules have been investigated both as potential targets for treatment and as potential biomarkers of estimation or early diagnosis of NP.
Further elucidation of underlying mechanisms of CINP may yield a new vision for targeted therapy of NCP.

There is a rapidly growing body of evidence demonstrating that spinal microglia play an important role in the NP process. Under normal circumstances, microglia are resident macrophages derived from yolk-sac macrophages, and responsible for monitoring of the local environment and protection. ${ }^{194,195}$ After a peripheral nerve injury, they transform into active states by hypertrophy, new gene expression (purinergic cell-surface receptors), and proinflammatory cytokines in DRG. ${ }^{16,196}$ There are growing numbers of studies trying to elucidate the role of microglial activation and also the astrocyte role in the NP mechanism. ${ }^{17,197}$ Inhibition of microglia suppresses hypersensitivity to pain to innocuous stimuli (allodynia), which is one of the hallmarks of NP. In animal models, microglia-neuronal interaction was tested in CINP. ${ }^{28}$ It was shown that in rats treated with oxaliplatin, microglia reactivation occurred in the CNS; additionally, astrocytes proliferated and migrated to certain areas of the brain, supporting the hypothesis of astrocyte-related longterm pain persistence. ${ }^{28}$ Spinal microglia might be a promising target for treating NCP and CINP.

Ceramide is a proinflammatory and proapoptotic molecule derived from sphingomyelin and by de novo synthesis from serine palmitodyltransferase. ${ }^{198}$ In addition to established roles in inflammation and cancer, there are emerging data of their modulatory role in the peripheral and central sensitization of pain processing. ${ }^{199}$ Preclinical and clinical pharmacological studies will provide fundamental information about the role of ceramide in pain, and may offer a multilevel approach for the development of analgesics.

Cancer pain includes both the nociceptive and NP components. Cancer itself may be the cause of pain, or treatment processes and pharmaceuticals may lead to pain. NCP is resistant to treatment, and may continue to be present in patients even when the cancer is cured. WHO guidance is still valid for cancer pain, and there is a growing body of evidence for the addition of coanalgesics to treatment. Diagnosis of NCP is burdensome, since most of the time, pain is underreported by patients unless they are asked, and NCP is underrecognized by physicians. Doctors other than pain specialists are afraid of pain and NCP as an esoteric topic. There are no well-established diagnostic tools that can be used by practitioners easily to make the differential diagnosis of NP in everyday practice. Once a diagnosis of NCP is made, opioids, antidepressants, and anticonvulsants should be prescribed. The clinical beneficence of opioids and coanalgesics outweighs the adverse effects. 
The armory of NP is broad and is getting broader as interest in pain mechanisms increases. In accordance with WHO guidelines, appropriate induction of coanalgesics should be recommended. Combination therapies with different pathophysiologic mechanisms are especially supported. This kind of polypharmacy may effectively relieve pain with acceptable side effects. Basic scientific developments and findings have shown new pathophysiologic pathways in NP and NCP. More clinical studies are needed to understand $\mathrm{NCP}$ and treat patients accordingly. In the future, new specific disease-modifying agents are expected.

\section{Disclosure}

The authors report no conflicts of interest in this work.

\section{References}

1. Merskey H, Bogduk N. Classification of Chronic Pain: Descriptions of Chronic Pain Syndromes and Definitions of Pain Terms. 2nd ed. Seattle: IASP; 2012.

2. Baranowski A, Berger R, Buffington T, et al. Classification of chronic pain. In: Baranowski A, editor. 4th ed. 2012. Available from: http:// www.iasp-pain.org/PublicationsNews/Content.aspx?ItemNumber=16 73\&navItemNumber=677. Accessed August 11, 2013.

3. Bjorgul K, NovicoffWM, Saleh KJ. American Society of Anesthesiologist Physical Status score may be used as a comorbidity index in hip fracture surgery. J Arthroplasty. 2010;25(Suppl 6):134-137.

4. Rief W, Kaasa S, Jensen R, et al. New proposals for the International Classification of Diseases-11 revision of pain diagnoses. J Pain. 2012;13(4):305-316.

5. Polomano RC, Farrar JT. Pain and neuropathy in cancer survivors. Surgery, radiation, and chemotherapy can cause pain; research could improve its detection and treatment. Am J Nurs. 2006;106(Suppl 3): $39-47$.

6. Chong MS, Bajwa ZH. Diagnosis and treatment of neuropathic pain. J Pain Symptom Manage. 2003;25(Suppl 5):S4-S11.

7. Treede RD, Jensen TS, Campbell JN, et al. Neuropathic pain: redefinition and a grading system for clinical and research purposes. Neurology. 2008;70(18):1630-1635.

8. Auret K, Schug SA. Pain management for the cancer patient - current practice and future developments. Best Pract Res Clin Anaesthesiol. 2013;27(4):545-561.

9. Swarm RA, Abernethy AP, Anghelescu DL, et al. Adult cancer pain. J Natl Compr Canc Netw. 2013;11(8):992-1022.

10. Baron R, Binder A, Wasner G. Neuropathic pain: diagnosis, pathophysiological mechanisms, and treatment. Lancet Neurol. 2010;9(8): 807-819.

11. Attal N. Neuropathic pain: mechanisms, therapeutic approach, and interpretation of clinical trials. Continuum. 2012;18(1):161-175.

12. Woolf CJ, Salter MW. Neuronal plasticity: increasing the gain in pain. Science. 2000;288(5472):1765-1769.

13. Siqueira SR, Alves B, Malpartida HM, Teixeira MJ, Siqueira JT. Abnormal expression of voltage-gated sodium channels Nav1.7, Nav1.3 and Nav1.8 in trigeminal neuralgia. Neuroscience. 2009;164(2): 573-577.

14. Dib-Hajj SD, Black JA, Waxman SG. Voltage-gated sodium channels: therapeutic targets for pain. Pain Med. 2009;10(7):1260-1269.

15. Bahia PK, Suzuki R, Benton DC, et al. A functional role for smallconductance calcium-activated potassium channels in sensory pathways including nociceptive processes. $J$ Neurosci. 2005;25(14): 3489-3498.
16. Tsuda M, Beggs S, Salter MW, Inoue K. Microglia and intractable chronic pain. Glia. 2013;61(1):55-61.

17. Cheng KI, Wang HC, Chuang YT, et al. Persistent mechanical allodynia positively correlates with an increase in activated microglia and increased P-p38 mitogen-activated protein kinase activation in streptozotocin-induced diabetic rats. Eur J Pain. 2014;18(2):162-173.

18. Goudas LC, Bloch R, Gialeli-Goudas M, Lau J, Carr DB. The epidemiology of cancer pain. Cancer Invest. 2005;23(2):182-190.

19. van den Beuken-van Everdingen MH, de Rijke JM, Kessels AG, Schouten HC, van Kleef M, Patijn J. Prevalence of pain in patients with cancer: a systematic review of the past 40 years. Ann Oncol. 2007;18(9): $1437-1449$.

20. Rayment C, Hjermstad MJ, Aass N, et al. Neuropathic cancer pain: prevalence, severity, analgesics and impact from the European Palliative Care Research Collaborative-Computerised Symptom Assessment study. Palliat Med. 2013;27(8):714-721.

21. Foley KM. Acute and chronic cancer pain syndromes. In: Hanks G, Cherny NI, Christakis NA, Fallon M, Kaasa S, Portenoy RK. Oxford Textbook of Palliative Medicine. 3rd ed. New York: Oxford University Press; 2004:298.

22. Bennett MI, Rayment C, Hjermstad M, Aass N, Caraceni A, Kaasa S. Prevalence and aetiology of neuropathic pain in cancer patients: a systematic review. Pain. 2012;153(2):359-365.

23. Neal AJ, Qian MY, Clinch AS, Le BH. Orthostatic hypotension secondary to CRMP-5 paraneoplastic autonomic neuropathy. J Clin Neurosci. Epub October 11, 2013.

24. Paice JA. Mechanisms and management of neuropathic pain in cancer. J Support Oncol. 2003;1(2):107-120.

25. Urch CE, Dickenson AH. Neuropathic pain in cancer. Eur J Cancer. 2008;44(8):1091-1096.

26. Christo PJ, Mazloomdoost D. Cancer pain and analgesia. Ann NY Acad Sci. 2008;1138:278-298.

27. Wodarski R, Clark AK, Grist J, Marchand F, Malcangio M. Gabapentin reverses microglial activation in the spinal cord of streptozotocininduced diabetic rats. Eur J Pain. 2009;13(8):807-811.

28. Di Cesare Mannelli L, Pacini A, Bonaccini L, Zanardelli M, Mello T, Ghelardini C. Morphologic features and glial activation in rat oxaliplatin-dependent neuropathic pain. J Pain. 2013;14(12): $1585-1600$.

29. Demir IE, Schorn S, Schremmer-Danninger E, et al. Perineural mast cells are specifically enriched in pancreatic neuritis and neuropathic pain in pancreatic cancer and chronic pancreatitis. PloS One. 2013;8(3):e60529.

30. Demir IE, Schafer KH, Tieftrunk E, Friess H, Ceyhan GO. Neural plasticity in the gastrointestinal tract: chronic inflammation, neurotrophic signals, and hypersensitivity. Acta Neuropathol. 2013;125(4):491-509.

31. Wang K, Demir IE, D'Haese JG, et al. The neurotrophic factor neurturin contributes toward an aggressive cancer cell phenotype, neuropathic pain and neuronal plasticity in pancreatic cancer. Carcinogenesis. 2014;35(1):103-113.

32. Mantyh PW, Clohisy DR, Koltzenburg M, Hunt SP. Molecular mechanisms of cancer pain. Nat Rev Cancer. 2002;2(3):201-209.

33. Delaney A, Fleetwood-Walker SM, Colvin LA, Fallon M. Translational medicine: cancer pain mechanisms and management. Br J Anaesth. 2008;101(1):87-94.

34. Colvin L, Fallon M. Challenges in cancer pain management - bone pain. Eur J Cancer. 2008;44(8):1083-1090.

35. Caraceni A, Martini C, Zecca E, et al. Breakthrough pain characteristics and syndromes in patients with cancer pain. An international survey. Palliat Med. 2004;18(3):177-183.

36. Windebank AJ, Grisold W. Chemotherapy-induced neuropathy. J Peripher Nerv Syst. 2008;13(1):27-46.

37. Antoine JC, Camdessanche JP. Peripheral nervous system involvement in patients with cancer. Lancet Neurol. 2007;6(1):75-86.

38. Koike H, Tanaka F, Sobue G. Paraneoplastic neuropathy: wideranging clinicopathological manifestations. Curr Opin Neurol. 2011;24(5):504-510. 
39. Sindic CJ. Infectious neuropathies. Curr Opin Neurol. 2013;26(5): 510-515.

40. Yawn BP, Gilden D. The global epidemiology of herpes zoster. Neurology. 2013;81(10):928-930.

41. Fashner J, Bell AL. Herpes zoster and postherpetic neuralgia: prevention and management. Am Fam Physician. 2011;83(12):1432-1437.

42. Gilden D, Nagel MA, Cohrs RJ, Mahalingam R. The variegate neurological manifestations of varicella zoster virus infection. Curr Neurol Neurosci Rep. 2013;13(9):374.

43. Kim SR, Khan F, Tyring SK. Varicella zoster: an update on current treatment options and future perspectives. Expert Opin Pharmacother. 2014;15(1):61-71.

44. Angarone M. Epidemiology and prevention of viral infections in patients with hematologic malignancies. Infect Disord Drug Targets. 2011;11(1):27-33.

45. Weitzman D, Shavit O, Stein M, Cohen R, Chodick G, Shalev V. A population based study of the epidemiology of herpes zoster and its complications. $J$ Infect. 2013;67(5):463-469.

46. Habel LA, Ray GT, Silverberg MJ, et al. The epidemiology of herpes zoster in patients with newly diagnosed cancer. Cancer Epidemiol Biomarkers Prev. 2013;22(1):82-90.

47. Garzón-Rodríguez CG, Lyras L, Gayoso LO, et al. Cancer-related neuropathic pain in out-patient oncology clinics: a European survey. BMC Palliat Care. 2013;12(1):41.

48. Fairchild A. Under-treatment of cancer pain. Curr Opin Support Palliat Care. 2010;4(1):11-15.

49. Shimozuma K, Ohashi Y, Takeuchi A, et al. Feasibility and validity of the Patient Neurotoxicity Questionnaire during taxane chemotherapy in a phase III randomized trial in patients with breast cancer: N-SAS BC 02. Support Care Cancer. 2009;17(12):1483-1491.

50. Kuroi K, Shimozuma K, Ohashi Y, et al. Prospective assessment of chemotherapy-induced peripheral neuropathy due to weekly paclitaxel in patients with advanced or metastatic breast cancer (CSP-HOR 02 study). Support Care Cancer. 2009;17(8):1071-1080.

51. Giglio P, Gilbert MR. Neurologic complications of cancer and its treatment. Curr Oncol Rep. 2010;12(1):50-59.

52. Kaley TJ, Deangelis LM. Therapy of chemotherapy-induced peripheral neuropathy. Br J Haematol. 2009;145(1):3-14.

53. Farquhar-Smith P. Chemotherapy-induced neuropathic pain. Curr Opin Support Palliat Care. 2011;5(1):1-7.

54. Roelofs RI, Hrushesky W, Rogin J, Rosenberg L. Peripheral sensory neuropathy and cisplatin chemotherapy. Neurology. 1984;34(7):934-938.

55. Albers JW, Chaudhry V, Cavaletti G, Donehower RC. Interventions for preventing neuropathy caused by cisplatin and related compounds. Cochrane Database Syst Rev. 2011;(2):CD005228.

56. Park SB, Lin CS, Krishnan AV, Goldstein D, Friedlander ML, Kiernan MC. Oxaliplatin-induced neurotoxicity: changes in axonal excitability precede development of neuropathy. Brain. 2009; 132(Pt 10):2712-2723.

57. Ta LE, Espeset L, Podratz J, Windebank AJ. Neurotoxicity of oxaliplatin and cisplatin for dorsal root ganglion neurons correlates with platinumDNA binding. Neurotoxicology. 2006;27(6):992-1002.

58. DormannAJ, GrunewaldT, Wigginghaus B, Huchzermeyer H. Gemcitabineassociated autonomic neuropathy. Lancet. 1998;351(9103):644.

59. Reeves BN, Dakhil SR, Sloan JA, et al. Further data supporting that paclitaxel-associated acute pain syndrome is associated with development of peripheral neuropathy: North Central Cancer Treatment Group trial N08C1. Cancer. 2012;118(20):5171-5178.

60. Lee JJ, Swain SM. Peripheral neuropathy induced by microtubulestabilizing agents. J Clin Oncol. 2006;24(10):1633-1642.

61. Hausheer FH, Schilsky RL, Bain S, Berghorn EJ, Lieberman F. Diagnosis, management, and evaluation of chemotherapy-induced peripheral neuropathy. Semin Oncol. 2006;33(1):15-49.

62. Gradishar WJ, Krasnojon D, Cheporov S, et al. Significantly longer progression-free survival with nab-paclitaxel compared with docetaxel as first-line therapy for metastatic breast cancer. J Clin Oncol. 2009;27(22):3611-3619.
63. Gradishar WJ, Tjulandin S, Davidson N, et al. Phase III trial of nanoparticle albumin-bound paclitaxel compared with polyethylated castor oil-based paclitaxel in women with breast cancer. J Clin Oncol. 2005;23(31):7794-7803.

64. de Bono JS, Oudard S, Ozguroglu M, et al. Prednisone plus cabazitaxel or mitoxantrone for metastatic castration-resistant prostate cancer progressing after docetaxel treatment: a randomised open-label trial. Lancet. 2010;376(9747):1147-1154.

65. Verstappen CC, Koeppen S, Heimans JJ, et al. Dose-related vincristineinduced peripheral neuropathy with unexpected off-therapy worsening. Neurology. 2005;64(6):1076-1077.

66. Weintraub M, Adde MA, Venzon DJ, et al. Severe atypical neuropathy associated with administration of hematopoietic colony-stimulating factors and vincristine. J Clin Oncol. 1996;14(3):935-940.

67. Legha SS. Vincristine neurotoxicity. Pathophysiology and management. Med Toxicol. 1986;1(6):421-427.

68. DeAngelis LM, Posner JB. Side effects of chemotherapy. In: Neurologic Complications of Cancer. 2nd ed. New York: Oxford University Press; 2009:447.

69. Mokhtar GM, Shaaban SY, Elbarbary NS, Fayed WA. A trial to assess the efficacy of glutamic acid in prevention of vincristine-induced neurotoxicity in pediatric malignancies: a pilot study. $J$ Pediatr Hematol Oncol. 2010;32(8):594-600.

70. Argyriou AA, Marmiroli P, Cavaletti G, Kalofonos HP. Epothiloneinduced peripheral neuropathy: a review of current knowledge. J Pain Symptom Manage. 2011;42(6):931-940.

71. Cortes J, O'Shaughnessy J, Loesch D, et al. Eribulin monotherapy versus treatment of physician's choice in patients with metastatic breast cancer (EMBRACE): a phase 3 open-label randomised study. Lancet. 2011;377(9769):914-923.

72. Rajkumar SV, Rosinol L, Hussein M, et al. Multicenter, randomized, double-blind, placebo-controlled study of thalidomide plus dexamethasone compared with dexamethasone as initial therapy for newly diagnosed multiple myeloma. J Clin Oncol. 2008;26(13): 2171-2177.

73. Plasmati R, Pastorelli F, Cavo M, et al. Neuropathy in multiple myeloma treated with thalidomide: a prospective study. Neurology. 2007;69(6): 573-581.

74. Murphy PT, O'Donnell JR. Thalidomide induced impotence in male hematology patients: a common but ignored complication? Haematologica. 2007;92(10):1440.

75. Dimopoulos MA, Chen C, Spencer A, et al. Long-term follow-up on overall survival from the MM-009 and MM-010 phase III trials of lenalidomide plus dexamethasone in patients with relapsed or refractory multiple myeloma. Leukemia. 2009;23(11):2147-2152.

76. Rajkumar SV, Richardson PG, Hideshima T, Anderson KC. Proteasome inhibition as a novel therapeutic target in human cancer. J Clin Oncol. 2005;23(3):630-639.

77. Goy A, Younes A, McLaughlin P, et al. Phase II study of proteasome inhibitor bortezomib in relapsed or refractory B-cell non-Hodgkin's lymphoma. J Clin Oncol. 2005;23(4):667-675.

78. Kobrinsky B, Joseph SO, Muggia F, et al. A phase I and pharmacokinetic study of oxaliplatin and bortezomib: activity, but dose-limiting neurotoxicity. Cancer Chemother Pharmacol. 2013;72(5): 1073-1078.

79. Harvey RD, Owonikoko TK, Lewis CM, et al. A phase 1 Bayesian dose selection study of bortezomib and sunitinib in patients with refractory solid tumor malignancies. Br J Cancer. 2013;108(4):762-765.

80. Cavaletti G, Jakubowiak AJ. Peripheral neuropathy during bortezomib treatment of multiple myeloma: a review of recent studies. Leuk Lymphoma. 2010;51(7):1178-1187.

81. Richardson PG, Delforge M, Beksac M, et al. Management of treatmentemergent peripheral neuropathy in multiple myeloma. Leukemia. 2012;26(4):595-608.

82. Chaudhry V, Cornblath DR, Polydefkis M, Ferguson A, Borrello I. Characteristics of bortezomib- and thalidomide-induced peripheral neuropathy. J Peripher Nerv Syst. 2008;13(4):275-282. 
83. Lawasut $\mathrm{P}$, Chauhan D, Laubach J, et al. New proteasome inhibitors in myeloma. Curr Hematol Malig Rep. 2012;7(4):258-266.

84. Siegel DS, Martin T, Wang M, et al. A phase 2 study of single-agent carfilzomib (PX-171-003-A1) in patients with relapsed and refractory multiple myeloma. Blood. 2012;120(14):2817-2825.

85. Daut RL, Cleeland CS, Flanery RC. Development of the Wisconsin Brief Pain Questionnaire to assess pain in cancer and other diseases. Pain. 1983;17(2):197-210.

86. Fishman B, Pasternak S, Wallenstein SL, Houde RW, Holland JC, Foley KM. The Memorial Pain Assessment Card. A valid instrument for the evaluation of cancer pain. Cancer. 1987;60(5): $1151-1158$.

87. Bennett MI, Attal N, Backonja MM, et al. Using screening tools to identify neuropathic pain. Pain. 2007;127(3):199-203.

88. Attal N, Cruccu G, Baron R, et al. EFNS guidelines on the pharmacological treatment of neuropathic pain: 2010 revision. Eur J Neurol. 2010;17(9):1113-1188.

89. Cleeland CS, Farrar JT, Hausheer FH. Assessment of cancer-related neuropathy and neuropathic pain. Oncologist. 2010;15 Suppl 2: $13-18$.

90. Cruccu G, Truini A. Neuropathic pain and its assessment. Surg Oncol. 2010;19(3):149-154.

91. Brzeziński K. Chemotherapy-induced peripheral neuropathy. Part II. Prevention. Contemp Oncol (Pozn). 2012;16(3):258-261.

92. Ripamonti CI, Santini D, Maranzano E, Berti M, Roila F. Management of cancer pain: ESMO Clinical Practice Guidelines. Ann Oncol. 2012;23 Suppl 7:vii139-vii154.

93. Walker VA, Hoskin PJ, Hanks GW, White ID. Evaluation of WHO analgesic guidelines for cancer pain in a hospital-based palliative care unit. J Pain Symptom Manage. 1988;3(3):145-149.

94. World Health Organization. Scoping document for WHO guidelines for the pharmacological treatment of persisting pain in adults with medical illnesses. 2012. Available from: http://www.who.int/medicines/areas/ quality_safety/Scoping_WHO_GLs_PersistPainAdults_webversion. pdf. Accessed October 8, 2013.

95. McNicol E, Strassels SA, Goudas L, Lau J, Carr DB. NSAIDS or paracetamol, alone or combined with opioids, for cancer pain. Cochrane Database Syst Rev. 2005;(1):CD005180.

96. Nabal M, Librada S, Redondo MJ, Pigni A, Brunelli C, Caraceni A. The role of paracetamol and nonsteroidal anti-inflammatory drugs in addition to WHO Step III opioids in the control of pain in advanced cancer. A systematic review of the literature. Palliat Med. 2012;26(4): 305-312.

97. Caraceni A, Hanks G, Kaasa S, et al. Use of opioid analgesics in the treatment of cancer pain: evidence-based recommendations from the EAPC. Lancet Oncol. 2012;13(2):e58-e68.

98. Lotsch J. Opioid metabolites. J Pain Symptom Manage. 2005; 29(Suppl 5):S10-S24.

99. Duhmke RM, Cornblath DD, Hollingshead JR. Tramadol for neuropathic pain. Cochrane Database Syst Rev. 2004;(2):CD003726.

100. Mercadante S, Porzio G, Ferrera P, et al. Tapentadol in cancer pain management: a prospective open-label study. Curr Med Res Opin. 2012;28(11):1775-1779.

101. King S, Forbes K, Hanks GW, Ferro CJ, Chambers EJ. A systematic review of the use of opioid medication for those with moderate to severe cancer pain and renal impairment: a European Palliative Care Research Collaborative opioid guidelines project. Palliat Med. 2011;25(5):525-552.

102. Gaertner J, Schiessl C. Cancer pain management: what's new? Curr Pain Headache Rep. 2013;17(4):328.

103. Ahmedzai SH, Nauck F, Bar-Sela G, Bosse B, Leyendecker P, Hopp M. A randomized, double-blind, active-controlled, double-dummy, parallel-group study to determine the safety and efficacy of oxycodone/ naloxone prolonged-release tablets in patients with moderate/severe, chronic cancer pain. Palliat Med. 2012;26(1):50-60.

104. Paice JA, Ferrell B. The management of cancer pain. CA Cancer J Clin. 2011;61(3):157-182.
105. Minozzi S, Amato L, Davoli M. Development of dependence following treatment with opioid analgesics for pain relief: a systematic review. Addiction. 2013;108(4):688-698.

106. Fallon M, Hanks G, Cherny N. Principles of control of cancer pain. BMJ. 2006;332(7548):1022-1024.

107. Guindon J, Walczak JS, Beaulieu P. Recent advances in the pharmacological management of pain. Drugs. 2007;67(15): 2121-2133.

108. Knotkova H, Pappagallo M. Adjuvant analgesics. Med Clin North Am. 2007;91(1):113-124.

109. Fallon MT. Neuropathic pain in cancer. Br J Anaesth. 2013;111(1): $105-111$.

110. Dworkin RH, O'Connor AB, Backonja M, et al. Pharmacologic management of neuropathic pain: evidence-based recommendations. Pain. 2007;132(3):237-251.

111. Hempenstall K, Nurmikko TJ, Johnson RW, A'Hern RP, Rice AS. Analgesic therapy in postherpetic neuralgia: a quantitative systematic review. PLoS Med. 2005;2(7):e164.

112. Saarto T, Wiffen PJ. Antidepressants for neuropathic pain: a Cochrane review. J Neurol Neurosurg Psychiatry. 2010;81(12):1372-1373.

113. Sindrup SH, Bach FW, Madsen C, Gram LF, Jensen TS. Venlafaxine versus imipramine in painful polyneuropathy: a randomized, controlled trial. Neurology. 2003;60(8):1284-1289.

114. Rowbotham MC, Goli V, Kunz NR, Lei D. Venlafaxine extended release in the treatment of painful diabetic neuropathy: a double-blind, placebo-controlled study. Pain. 2004;110(3):697-706.

115. Durand JP, Deplanque G, Montheil V, et al. Efficacy of venlafaxine for the prevention and relief of oxaliplatin-induced acute neurotoxicity: results of EFFOX, a randomized, double-blind, placebo-controlled phase III trial. Ann Oncol. 2012;23(1):200-205.

116. Durand JP, Goldwasser F. Dramatic recovery of paclitaxel-disabling neurosensory toxicity following treatment with venlafaxine. Anticancer Drugs. 2002;13(7):777-780.

117. Kajdasz DK, Iyengar S, Desaiah D, et al. Duloxetine for the management of diabetic peripheral neuropathic pain: evidence-based findings from post hoc analysis of three multicenter, randomized, double-blind, placebo-controlled, parallel-group studies. Clin Ther. 2007;29 Suppl:2536-2546.

118. Veves A, Backonja M, Malik RA. Painful diabetic neuropathy: epidemiology, natural history, early diagnosis, and treatment options. Pain Med. 2008;9(6):660-674.

119. Irving GA. Contemporary assessment and management of neuropathic pain. Neurology. 2005;64(12 Suppl 3):S21-S27.

120. Lunn MP, Hughes RA, Wiffen PJ. Duloxetine for treating painful neuropathy, chronic pain or fibromyalgia. Cochrane Database Syst Rev. 2014;1:CD007115.

121. Amr YM, Yousef AA. Evaluation of efficacy of the perioperative administration of venlafaxine or gabapentin on acute and chronic postmastectomy pain. Clin J Pain. 2010;26(5):381-385.

122. Piccolo J, Kolesar JM. Prevention and treatment of chemotherapyinduced peripheral neuropathy. Am J Health Syst Pharm. 2014;71(1): $19-25$.

123. Semenchuk MR, Sherman S, Davis B. Double-blind, randomized trial of bupropion SR for the treatment of neuropathic pain. Neurology. 2001;57(9):1583-1588.

124. Vadalouca A, Raptis E, Moka E, Zis P, Sykioti P, Siafaka I. Pharmacological treatment of neuropathic cancer pain: a comprehensive review of the current literature. Pain Pract. 2012;12(3):219-251.

125. Caraceni A, Zecca E, Bonezzi C, et al. Gabapentin for neuropathic cancer pain: a randomized controlled trial from the Gabapentin Cancer Pain Study Group. J Clin Oncol. 2004;22(14):2909-2917.

126. Tsavaris N, Kopterides P, Kosmas C, et al. Gabapentin monotherapy for the treatment of chemotherapy-induced neuropathic pain: a pilot study. Pain Med. 2008;9(8):1209-1216.

127. Arai YC, Matsubara T, Shimo K, et al. Low-dose gabapentin as useful adjuvant to opioids for neuropathic cancer pain when combined with low-dose imipramine. J Anesth. 2010;24(3):407-410. 
128. Lossignol DA, Plehiers B, Body JJ. [Gabapentin (Neurontin) and cancer pain: a pilot study]. Rev Med Brux. 2004;25(5):429-435. French.

129. Mishra S, Bhatnagar S, Goyal GN, Rana SP, Upadhya SP. A comparative efficacy of amitriptyline, gabapentin, and pregabalin in neuropathic cancer pain: a prospective randomized double-blind placebo-controlled study. Am J Hosp Palliat Care. 2012;29(3):177-182.

130. Yan PZ, Butler PM, Kurowski D, Perloff MD. Beyond neuropathic pain: gabapentin use in cancer pain and perioperative pain. Clin $J$ Pain. Epub Novemer 25, 2013.

131. Ross JR, Waight C, Riley J, Broadley K. Gabapentin: resistant neuropathic pain and malignancy. Palliat Med. 2001;15(4):348-349.

132. Navarro A, Saldaña MT, Pérez C, Torrades S, Rejas J. Patient-reported outcomes in subjects with neuropathic pain receiving pregabalin: evidence from medical practice in primary care settings. Pain Med. 2010;11(5):719-731.

133. Wiffen PJ, Derry S, Moore RA. Lamotrigine for chronic neuropathic pain and fibromyalgia in adults. Cochrane Database Syst Rev. 2013;12:CD006044.

134. Zakrzewska JM, McMillan R. Trigeminal neuralgia: the diagnosis and management of this excruciating and poorly understood facial pain. Postgrad Med J. 2011;87(1028):410-416.

135. Okon T. Ketamine: an introduction for the pain and palliative medicine physician. Pain Physician. 2007;10(3):493-500.

136. Sindrup SH, Jensen TS. Efficacy of pharmacological treatments of neuropathic pain: an update and effect related to mechanism of drug action. Pain. 1999;83(3):389-400.

137. Noppers I, Niesters M, Aarts L, Smith T, Sarton E, Dahan A. Ketamine for the treatment of chronic non-cancer pain. Expert Opin Pharmacother. 2010;11(14):2417-2429.

138. Hardy J, Quinn S, Fazekas B, et al. Randomized, double-blind, placebo-controlled study to assess the efficacy and toxicity of subcutaneous ketamine in the management of cancer pain. $J$ Clin Oncol. 2012;30(29):3611-3617.

139. Jackson K, Franco M, William L, et al. Ketamine and cancer pain the reports of my death have been greatly exaggerated. J Clin Oncol. 2013;31(10):1373-1374.

140. Crosby V, Wilcock A, Corcoran R. The safety and efficacy of a single dose (500 $\mathrm{mg}$ or $1 \mathrm{~g}$ ) of intravenous magnesium sulfate in neuropathic pain poorly responsive to strong opioid analgesics in patients with cancer. J Pain Symptom Manage. 2000;19(1): 35-39.

141. Sawynok J. Topical analgesics for neuropathic pain: preclinical exploration, clinical validation, future development. Eur J Pain. Epub September 24, 2013.

142. Argoff CE, Barkin RL, McCarberg B, Stanos SP, Galluzzi KE, Arnstrein PM. Topical analgesics in the management of acute and chronic pain. Postgrad Med. 2013;125(4 Suppl 1):3-41.

143. Rowbotham MC, Davies PS, Verkempinck C, Galer BS. Lidocaine patch: double-blind controlled study of a new treatment method for post-herpetic neuralgia. Pain. 1996;65(1):39-44.

144. Galer BS, Rowbotham MC, Perander J, Friedman E. Topical lidocaine patch relieves postherpetic neuralgia more effectively than a vehicle topical patch: results of an enriched enrollment study. Pain. 1999;80(3):533-538.

145. Meier T, Wasner G, Faust M, et al. Efficacy of lidocaine patch 5\% in the treatment of focal peripheral neuropathic pain syndromes: a randomized, double-blind, placebo-controlled study. Pain. 2003;106(1-2): 151-158.

146. Connolly I, Zaleon C, Montagnini M. Management of severe neuropathic cancer pain: an illustrative case and review. Am J Hosp Palliat Care. 2013;30(1):83-90.

147. Jones VM, Moore KA, Peterson DM. Capsaicin 8\% topical patch (Qutenza) - a review of the evidence. J Pain Palliat Care Pharmacother. 2011;25(1):32-41.

148. Hoy SM. Tapentadol extended release: in adults with chronic pain. Drugs. 2012;72(3):375-393.
149. Buynak R, Shapiro DY, Okamoto A, et al. Efficacy and safety of tapentadol extended release for the management of chronic low back pain: results of a prospective, randomized, double-blind, placeboand active-controlled Phase III study. Expert Opin Pharmacother. 2010;11(11):1787-1804.

150. Afilalo M, Etropolski MS, Kuperwasser B, et al. Efficacy and safety of tapentadol extended release compared with oxycodone controlled release for the management of moderate to severe chronic pain related to osteoarthritis of the knee: a randomized, double-blind, placebo- and activecontrolled phase III study. Clin Drug Investig. 2010;30(8):489-505.

151. Merker M, Dinges G, Koch T, Kranke P, Morin AM. [Undesired side effects of tapentadol in comparison to oxycodone. A metaanalysis of randomized controlled comparative studies]. Schmerz. 2012;26(1):16-26. German.

152. Portenoy RK, Ganae-Motan ED, Allende S, et al. Nabiximols for opioid-treated cancer patients with poorly-controlled chronic pain: a randomized, placebo-controlled, graded-dose trial. J Pain. 2012;13(5):438-449.

153. Pertwee RG. Cannabinoid pharmacology: the first 66 years. $\mathrm{Br} J$ Pharmacol. 2006;147 Suppl 1:S163-S171.

154. Welch SP, Stevens DL. Antinociceptive activity of intrathecally administered cannabinoids alone, and in combination with morphine, in mice. J Pharmacol Exp Ther. 1992;262(1):10-18.

155. Desroches J, Bouchard JF, Gendron L, Beaulieu P. Involvement of cannabinoid receptors in peripheral and spinal morphine analgesia. Neuroscience. 2014;261:23-42.

156. Beijers AJ, Jongen JL, Vreugdenhil G. Chemotherapy-induced neurotoxicity: the value of neuroprotective strategies. Neth $\mathrm{J} \mathrm{Med}$. 2012;70(1):18-25.

157. Mijnhout GS, Alkhalaf A, Kleefstra N, Bilo HJ. Alpha lipoic acid: a new treatment for neuropathic pain in patients with diabetes? Neth J Med. 2010;68(4):158-162.

158. Kalkanis JG, Whitworth C, Rybak LP. Vitamin E reduces cisplatin ototoxicity. Laryngoscope. 2004;114(3):538-542.

159. Kottschade LA, Sloan JA, Mazurczak MA, et al. The use of vitamin E for the prevention of chemotherapy-induced peripheral neuropathy: results of a randomized phase III clinical trial. Support Care Cancer. 2011;19(11):1769-1777.

160. Berger A, Sadosky A, Dukes E, Edelsberg J, Oster G. Clinical characteristics and patterns of healthcare utilization in patients with painful neuropathic disorders in UK general practice: a retrospective cohort study. BMC Neurol. 2012;12:8.

161. Gilron I, Jensen TS, Dickenson AH. Combination pharmacotherapy for management of chronic pain: from bench to bedside. Lancet Neurol. 2013;12(11):1084-1095.

162. Chaparro LE, Wiffen PJ, Moore RA, Gilron I. Combination pharmacotherapy for the treatment of neuropathic pain in adults. Cochrane Database Syst Rev. 2012;7:CD008943.

163. Gatti A, Sabato AF, Occhioni R, Colini Baldeschi G, Reale C. Controlled-release oxycodone and pregabalin in the treatment of neuropathic pain: results of a multicenter Italian study. Eur Neurol. 2009;61(3):129-137.

164. Finnerup NB, Otto M, McQuay HJ, Jensen TS, Sindrup SH. Algorithm for neuropathic pain treatment: an evidence based proposal. Pain 2005;118(3):289-305.

165. Garassino MC, Piva S, La Verde N, et al. Randomised phase II trial (NCT00637975) evaluating activity and toxicity of two different escalating strategies for pregabalin and oxycodone combination therapy for neuropathic pain in cancer patients. PloS One. 2013;8(4):e59981.

166. Nishihara M, Arai YC, Yamamoto Y, et al. Combinations of lowdose antidepressants and low-dose pregabalin as useful adjuvants to opioids for intractable, painful bone metastases. Pain Physician. 2013;16(5):E547-E552.

167. Lazzari M, Sabato AF, Caldarulo C, et al. Effectiveness and tolerability of low-dose oral oxycodone/naloxone added to anticonvulsant therapy for noncancer neuropathic pain: an observational analysis. Curr Med Res Opin. Epub December 5, 2013. 
168. Bhaskar AK. Interventional management of cancer pain. Curr Opin Support Palliat Care. 2012;6(1):1-9.

169. Plancarte R, Guajardo-Rosas J, Reyes-Chiquete D, et al. Management of chronic upper abdominal pain in cancer: transdiscal blockade of the splanchnic nerves. Reg Anesth Pain Med. 2010;35(6):500-506.

170. Zhang WY, Li ZS, Jin ZD. Endoscopic ultrasound-guided ethanol ablation therapy for tumors. World J Gastroenterol. 2013;19(22): 3397-3403.

171. Harsh V, Viswanathan A. Surgical/radiological interventions for cancer pain. Curr Pain Headache Rep. 2013;17(5):331.

172. Falco FJ, Patel VB, Hayek SM, et al. Intrathecal infusion systems for long-term management of chronic non-cancer pain: an update of assessment of evidence. Pain Physician. 2013;16(Suppl 2): SE185-SE216.

173. Sheinfeld Gorin S, Krebs P, Badr H, et al. Meta-analysis of psychosocial interventions to reduce pain in patients with cancer. J Clin Oncol. 2012;30(5):539-547.

174. Garcia MK, McQuade J, Haddad R, et al. Systematic review of acupuncture in cancer care: a synthesis of the evidence. J Clin Oncol. 2013;31(7):952-960.

175. Maani CV, Shah MA, Hansen JJ, Fowler M, Maani EV, McGhee LL. Translational advances in pain and anesthesia for cancer patients. J Surg Oncol. 2012;105(5):488-493.

176. Stamer UM, Stüber F. Codeine and tramadol analgesic efficacy and respiratory effects are influenced by CYP2D6 genotype. Anaesthesia. 2007;62(12):1294-1295; author reply 1295-1296.

177. Stamer UM, Musshoff F, Kobilay M, Madea B, Hoeft A, Stuber F. Concentrations of tramadol and O-desmethyltramadol enantiomers in different CYP2D6 genotypes. Clin Pharmacol Ther. 2007;82(1): $41-47$.

178. Turabi A, Plunkett AR. The application of genomic and molecular data in the treatment of chronic cancer pain. J Surg Oncol. 2012;105(5): 494-501.

179. Wolfe D, Mata M, Fink DJ. Targeted drug delivery to the peripheral nervous system using gene therapy. Neurosci Lett. 2012;527(2): $85-89$.

180. Xu JM, Song ST, Feng FY, et al. Cobrotoxin-containing analgesic compound to treat chronic moderate to severe cancer pain: results from a randomized, double-blind, cross-over study and from an open-label study. Oncol Rep. 2006;16(5):1077-1084.

181. Wallace MS, Kosek PS, Staats P, Fisher R, Schultz DM, Leong M. Phase II, open-label, multicenter study of combined intrathecal morphine and ziconotide: addition of ziconotide in patients receiving intrathecal morphine for severe chronic pain. Pain Med. 2008;9(3): 271-281.

182. Wallace MS, Charapata SG, Fisher R, et al. Intrathecal ziconotide in the treatment of chronic nonmalignant pain: a randomized, doubleblind, placebo-controlled clinical trial. Neuromodulation. 2006;9(2): 75-86.

183. Staats PS, Yearwood T, Charapata SG, et al. Intrathecal ziconotide in the treatment of refractory pain in patients with cancer or AIDS: a randomized controlled trial. JAMA. 2004;291(1):63-70.

184. Ellis DJ, Dissanayake S, McGuire D, et al. Continuous intrathecal infusion of ziconotide for treatment of chronic malignant and nonmalignant pain over 12 months: a prospective, open-label study. Neuromodulation. 2008;11(1):40-49.

OncoTargets and Therapy

\section{Publish your work in this journal}

OncoTargets and Therapy is an international, peer-reviewed, open access journal focusing on the pathological basis of all cancers, potential targets for therapy and treatment protocols employed to improve the management of cancer patients. The journal also focuses on the impact of management programs and new therapeutic agents and protocols on
185. Hannon HE, Atchison WD. Omega-conotoxins as experimental tools and therapeutics in pain management. Mar Drugs. 2013;11(3): 680-699.

186. Marcil J, Walczak JS, Guindon J, Ngoc AH, Lu S, Beaulieu P. Antinociceptive effects of tetrodotoxin (TTX) in rodents. Br JAnaesth. 2006;96(6):761-768.

187. Patel MK, Gonzalez MI, Bramwell S, Pinnock RD, Lee K. Gabapentin inhibits excitatory synaptic transmission in the hyperalgesic spinal cord. Br J Pharmacol. 2000;130(8):1731-1734.

188. Hagen NA, Lapointe B, Ong-Lam M, et al. A multicentre open-label safety and efficacy study of tetrodotoxin for cancer pain. Curr Oncol. 2011;18(3):e109-e116.

189. Hagen NA, Fisher KM, Lapointe B, et al. An open-label, multi-dose efficacy and safety study of intramuscular tetrodotoxin in patients with severe cancer-related pain. J Pain Symptom Manage. 2007;34(2): 171-182.

190. Hagen NA, du Souich P, Lapointe B, et al. Tetrodotoxin for moderate to severe cancer pain: a randomized, double blind, parallel design multicenter study. J Pain Symptom Manage. 2008;35(4): 420-429.

191. Wang XM, Hamza M, Wu TX, Dionne RA. Upregulation of IL-6, IL-8 and CCL2 gene expression after acute inflammation: correlation to clinical pain. Pain. 2009;142(3):275-283.

192. Uceyler N, Kafke W, Riediger N, et al. Elevated proinflammatory cytokine expression in affected skin in small fiber neuropathy. Neurology. 2010;74(22):1806-1813.

193. Wang XM, Lehky TJ, Brell JM, Dorsey SG. Discovering cytokines as targets for chemotherapy-induced painful peripheral neuropathy. Cytokine. 2012;59(1):3-9.

194. Ginhoux F, Greter M, Leboeuf M, et al. Fate mapping analysis reveals that adult microglia derive from primitive macrophages. Science. 2010;330(6005):841-845.

195. Nimmerjahn A, Kirchhoff F, Helmchen F. Resting microglial cells are highly dynamic surveillants of brain parenchyma in vivo. Science. 2005;308(5726):1314-1318.

196. Tsuda M, Tozaki-Saitoh H, Inoue K. Purinergic system, microglia and neuropathic pain. Curr Opin Pharmacol. 2012;12(1):74-79.

197. Cheng KI, Wang HC, Chuang YT, et al. Persistent mechanical allodynia positively correlates with an increase in activated microglia and increased P-p38 mitogen-activated protein kinase activation in streptozotocin-induced diabetic rats. Eur J Pain. 2014;18(2):162-173.

198. Kolesnick R. The therapeutic potential of modulating the ceramide/ sphingomyelin pathway. J Clin Invest. 2002;110(1):3-8.

199. Salvemini D, Doyle T, Kress M, Nicol G. Therapeutic targeting of the ceramide-to-sphingosine 1-phosphate pathway in pain. Trends Pharmacol Sci. 2013;34(2):110-118.

200. Bennett GJ. Pathophysiology and animal models of cancer-related painful peripheral neuropathy. Oncologist. 2010;15 Suppl 2:9-12.

201. Dworkin RH, Backonja M, Rowbotham MC, et al. Advances in neuropathic pain: diagnosis, mechanisms, and treatment recommendations. Arch Neurol. 2003;60(11):1524-1534.

202. McNicol E, Horowicz-Mehler N, Fisk RA, et al. Management of opioid side effects in cancer-related and chronic noncancer pain: a systematic review. J Pain. 2003;4(5):231-256.

\section{Dovepress}

patient perspectives such as quality of life, adherence and satisfaction. The manuscript management system is completely online and includes a very quick and fair peer-review system, which is all easy to use. Visit http://www.dovepress.com/testimonials.php to read real quotes from published authors. 